\title{
LA PROYECCIÓN DE LAS CASAS DE LA ALTA NOBLEZA EN LAS SOCIEDADES POLÍTICAS REGIONALES: EL CASO SORIANO A FINES DE LA EDAD MEDIA
}

\author{
PROJECTION OF HIGH NOBILITY HOUSEHOLDS \\ IN THE REGIONAL POLITICAL SOCIETIES: \\ THE CASE OF SORIA AT THE END OF THE MIDDLE AGES
}

\author{
MÁXIMO Diago HERNANDO \\ Instituto de Historia, CSIC. Madrid
}

\begin{abstract}
Resumen: Se analiza la composición de las casas de tres linajes de la alta nobleza que poseyeron extensos estados señoriales en la región nororiental de Castilla, fronteriza con Aragón y Navarra: los Arellano, condes de Aguilar, los Mendoza, condes de Monteagudo, y los De La Cerda, duques de Medinaceli. Se da cuenta del origen social y geográfico de los integrantes de dichas casas, y se demuestra que estos linajes de alta nobleza mostraron interés por incorporar a sus casas miembros influyentes de los grupos gobernantes de las ciudades realengas del entorno, en especial de la ciudad de Soria.
\end{abstract}

Palabras clave: Corona de Castilla; Siglos XV y XVI; Alta nobleza; Clientelismo; Casas nobiliarias.

\begin{abstract}
Summary: The author analyses the composition of the households of three prominent families of the Castilian high nobility that possessed large seigneurial estates in the North West region of Castile, near the border with the kingdoms of Aragón and Navarra: the Arellano family, counts of Aguilar, the Mendoza family, counts of Monteagudo, and the De la Cerda family, dukes of Medinaceli. He gives information about the social and geographic origin of the members of these households, and he proves that these noble families were interested in the incorporation to their households of influential members of the oligarchies of the royal towns of the region, especially of the town of Soria.
\end{abstract}

Keywords: Crown of Castile; Fifteenth and Sixteenth centuries; High nobility; Clientelism; Noble households.

\section{SUMARIO}

I. La composición de las casas nobiliarias: perfil socioeconómico de sus miembros: 1 . Ascenso de familias hidalgas en el seno de las casas nobiliarias. 2. Perfil socioeconómico de los principales oficiales de las casas nobiliarias. 3. La remuneración de los servidores de las casas nobiliarias.- II. Proyección política de las casas nobiliarias sobre los concejos realengos: 1 . La casa de los señores de Merdinaceli. 2. La casa de los Mendoza, señores de Almazán. 3. La casa de los Arellano, señores de Cameros.- III. Conclusiones.

Durante el período de gobierno de la dinastía Trastamara tuvo lugar en las diferentes regiones de la Corona de Castilla una radical transformación del panorama político regional, a raíz de la consolidación de estados señoriales más o menos compactos que sirvieron de plataforma para que unos pocos 
linajes de alta nobleza se aupasen en cada región a la posición de protagonistas centrales de su vida política. Dichos linajes, en efecto, para afianzar su poder en los ámbitos regionales donde se concentraban sus señoríos, pusieron con frecuencia en marcha estrategias de constitución de amplias y bien ramificadas clientelas, a las que, además de sus propios vasallos, vecinos de sus lugares de señorío, incorporaron también a numerosos, y con frecuencia muy influyentes, vecinos de los concejos de realengo.

En el presente trabajo nos vamos a centrar en el análisis de este fenómeno en una región en particular, la que tenía como centro político la ciudad de Soria, que asumió en solitario su representación en Cortes desde comienzos del siglo $\mathrm{XV}$, para tratar de comprobar en qué medida durante este siglo y en las primeras décadas del siguiente las grandes casas nobles, con mayor implantación señorial en la zona, actuaron como polo de atracción para la población hidalga de toda la región, y muy en especial de la que estaba avecindada en los concejos de realengo, y por consiguiente se consolidaron como principales instancias estructuradoras de la correspondiente sociedad política provincial. Las casas nobles que tuvieron implantación señorial en la región soriana a partir del período Trastamara fueron muchas, y se contaron entre ellas desde las más preclaras representantes de la alta nobleza hasta otras de rango bastante más modesto, cuyos miembros no sobrepasaban la categoría de simples caballeros. Para simplificar, en el presente trabajo centraremos nuestra atención en las tres casas que, por un lado, mantuvieron una más estrecha vinculación con la ciudad de Soria, y por otro destacaron frente a sus semejantes por haber alcanzado durante el reinado de los Reyes Católicos un superior grado de distinción, al haber sido premiadas por la Monarquía con un título nobiliario. Nos referimos a la casa de los duques de Medinaceli, señores de esta villa soriana cabecera de una extensa comunidad de villa y Tierra, a caballo entre las actuales provincias de Soria y de Guadalajara, a la de los condes de Monteagudo, señores de Almazán, y a la de los condes de Aguilar, señores de Cameros y de Yanguas.

Estas tres grandes casas nobiliarias ofrecían a fines del siglo XV y comienzos del siglo XVI numerosos rasgos comunes, a la vez que importantes diferencias, que no podemos entrar a detallar aquí de forma particularizada. Ante todo nos interesa poner de manifiesto la incidencia que su presencia tuvo en el proceso de moldeamiento de la sociedad política provincial en esta época, que ofrece una evidente singularidad frente a momentos posteriores de la historia soriana precisamente debido a que entonces los nobles que estaban al frente de estas casas desplegaron una parte importante de su actividad política en sus propios lugares de señorío, porque todavía no habían adoptado el modo de vida absentista que después les fue propio. Por ello fue durante el siglo XV y en la primera mitad del siglo XVI cuando la vida política y social en la región soriana se vio en más alto grado influida por las decisiones tomadas por unos pocos miembros de linajes de alta nobleza, pertenecientes a las tres casas que acabamos de mencionar, que hicieron sentir sus efectos no sólo en los lugares de señorío sometidos directamente a su autoridad como titulares de la jurisdicción civil y criminal, sino también en los concejos de 
realengo, donde se esforzaron por reclutar a miembros de sus clientelas, con evidente éxito, pues no sólo consiguieron captar a numerosos individuos, sino también a algunos de los que ejercían mayor influencia en el terreno político, o disfrutaban de mayor reconocimiento social.

En el período que tomamos en consideración en el presente trabajo fue cuando las villas de señorío que lograron auparse a la categoría de capitales de estado señorial, por haber decidido sus señores fijar en ellas su residencia con carácter más estable, experimentaron uno de los momentos "dorados" de su trayectoria histórica, pues la presencia continuada de sus señores actuó entonces como factor dinamizador de primera magnitud para sus estructuras socioeconómicas. La más favorecida desde este punto de vista fue probablemente la villa de Almazán, como consecuencia del hecho de que ningún otro núcleo de población pudo competir con ella dentro del estado señorial como lugar preferido por sus señores para residir durante la mayor parte del año, acompañados por su familia y los demás miembros de su casa. Los condes de Monteagudo, del prolífico linaje de los Mendoza, habían reunido, en efecto, un estado señorial de dimensiones más bien modestas, todo él concentrado desde el punto de vista geográfico en la región soriana, en el que por lo demás predominaban los núcleos de población de marcado carácter rural. Almazán era con diferencia el núcleo con mayor potencial demográfico, y por ello su elección como capital del "estado señorial" carecía prácticamente de alternativas. La decisión de edificar un gran palacio en esta villa a orillas del Duero, que fue precisamente el que acogió al príncipe Juan, primogénito de los Reyes Católicos, y a los miembros de su Corte cuando se decidió poner casa propia a este heredero de la Corona, a raíz de concertarse su matrimonio con la princesa Margarita de Austria, contribuyó de forma determinante a que la presencia de los miembros del linaje Mendoza terminase consolidándose como un elemento fundamental de la vida social y política adnamantina durante la segunda mitad del siglo XV y en la primera mitad del siglo XVI. Ciertamente los condes de Monteagudo no permanecían, ni siquiera en esta época, todo el año en sus posesiones señoriales, sino que los viajes a la Corte, que en esta época mantenía un carácter decididamente itinerante, eran obligados y frecuentes, cuando no eran otros menesteres los que les mantenían alejados de sus tierras, como, por ejemplo, la participación en empresas bélicas, tales como la conquista del reino de Granada, o, varias décadas más tarde, la del reino de Navarra. Pero, por comparación con otras épocas, entendemos que su permanencia en sus señoríos fue en este período de tránsito entre el Medievo y la Edad Moderna mucho más habitual, y ello se dejó notar en la vida social y política de los mismos, que conocieron una fuerte impronta nobiliaria, bastante más intensa que en cualquier otro momento de su trayectoria histórica. Esto es particularmente cierto en el caso de la villa de Almazán, que adquirió a fines del Medievo una singular fisonomía en el panorama urbano de la región soriana como consecuencia precisamente de haber sido elegida por los condes de Monteagudo como capital estable de su estado señorial. En ella, en efecto, hemos podido calcular que en 1512 en torno al $16 \%$ de los vecinos eran miembros de la casa condal, que gozaban de 
importantes privilegios en forma de exención de impuestos, y que, además, se reservaban el desempeño de un número importante de oficios de gobierno local, en concreto la mitad de las regidurías, que se renovaban todos los años el día primero de enero ${ }^{1}$.

Por contraste con Almazán, en los estados señoriales de los duques de Medinaceli y de los condes de Aguilar, no encontramos un núcleo de población que experimentase en igual grado los efectos de la presencia de la casa señorial en sus estructuras sociopolíticas. En cierto modo podría buscarse un paralelo para Almazán en la villa de Medinaceli, pero su caso no es plenamente equiparable al de aquélla, puesto que no acaparó en igual grado la presencia señorial, debido a que los duques contaban también con otros importantes señoríos en una región muy alejada de Soria, en concreto, en Andalucía, donde les pertenecía El Puerto de Santa María. Y, cuando permanecieron en la región soriana, tampoco manifestaron una excluyente predilección por la villa de Medinaceli, sino que también permanecieron prolongadas temporadas en otras villas de sus señorío, como, por ejemplo, la de Cogolludo, donde también tuvieron a su disposición un palacio para residir en él. Y, por lo que respecta a los condes de Aguilar, su estado señorial, que al igual que el de los condes de Monteagudo estaba todo él concentrado desde el punto de vista geográfico, en este caso a caballo entre Soria, Cameros y Rioja, no contó, sin embargo, con ningún núcleo de población con suficiente potencial demográfico como para consolidarse como una auténtica "capital". Los señores de Cameros del linaje Arellano residieron ciertamente durante largas temporadas en su castillo de la villa serrana de Yanguas, que fue probablemente el lugar del estado señorial camerano sobre el que mayor impacto ejerció a todos los niveles la presencia de estos nobles, rodeados de sus familiares y servidores, en los siglos XV y XVI. Pero Yanguas en ningún momento llegó a constituir un núcleo de población con características urbanas propiamente dichas, puesto que su número de vecinos fue siempre muy modesto. Y por ello los condes de Aguilar nunca aspiraron a convertir dicha villa en una auténtica capital de su estado señorial, hasta el punto de que ni siquiera mostraron interés por fundar en ella alguna comunidad de mendicantes, como la debía haber en cualquier núcleo urbano que se preciase. Así nos lo corrobora por otra parte la constatación del hecho de que, cuando decidieron proceder a realizar fundaciones conventuales, con un evidente restraso respecto a otros linajes de alta nobleza de su entorno, prefirieron hacerlo en villas riojanas con mayores posibilidades de desarrollo demográfico, como eran Entrena, donde en 1503 fundaron un convento de clarisas, el de Nuestra Señora de los Ángeles del Paraíso de Viavero, y Nalda, donde en 1617 fundaron un convento de franciscanos, el de San Antonio ${ }^{2}$.

\footnotetext{
${ }^{1}$ Vid. Máximo Diago HeRnando, Almazán en época de los Reyes Católicos. Estructura social de una pequeña capital de estado séñorial, "En la España Medieval", 16 (1993), pp. 239-64.

${ }^{2}$ Vid. Miguel A. Moreno RAMíREZ DE ARELLANO, Claves para la fundación de un convento franciscano extramuros de la villa de Nalda, "Berceo", 120 (1991), pp. 83-102.
} 
Aunque las consecuencias de la presencia señorial difirieron, pues, de forma apreciable de unos a otros núcleos dentro de la región soriana, en conjunto cabe afirmar que durante el siglo XV y en la primera mitad del siglo XVI fue cuando las poblaciones de señorío de esta región se vieron afectadas en mayor grado en sus estructuras socioeconómicas y políticas, y en muchos aspectos de su vida cotidiana, por dicha presencia, por ser entonces cuando ésta alcanzó su máxima intensidad. Conforme fue avanzando el siglo XVI, sin embargo, todos los representantes de la alta nobleza en la región soriana comenzaron a distanciarse de sus lugares de señorío, en los que en adelante residieron cada vez de forma más esporádica, bien porque prefirieron permanecer en la Corte, a la sombra del rey, sobre todo cuando ésta se fijó definitivamente en Madrid, o bien porque debieron residir fuera de Castilla, en Europa o en América, desempeñando cargos de gobernadores y virreyes, u otros de carácter militar o diplomático. Y esta evolución tuvo como principal corolario el hecho de que las villas de señorío que, gracias a la presencia de sus señores, habían constituido importantes puntos de referencia para la vida social y política "provincial" hasta el acceso al trono castellano de los Habsburgo, terminaron resultando en gran medida desplazadas en el desempeño de esta función por las grandes ciudades del realengo, en nuestro caso en particular por la ciudad de Soria, única con derecho a enviar procuradores a Cortes desde comienzos del siglo XV. Y, en efecto, a partir de la segunda mitad del siglo XVI, y con más intensidad a partir del siglo XVII, fue hacia Soria hacia donde se pasaron a dirigir todas las miradas de cuantas familias deseaban representar algo en la sociedad política provincial. De ahí que no fueran pocas las familias residentes en villas de señorío que, sobre todo en el transcurso del siglo XVII, se esforzaron por adquirir mediante compra o por otra vía un oficio de regidor en la ciudad del Duero, cuando no optaron directamente por trasladar a ella su residencia, por considerar que ofrecía mejores condiciones para el desarrollo de una carrera política mínimamente ambiciosa que las decadentes villas señoriales, despojadas de la presencia dinamizadora de sus señores, ausentes en la Corte o en otros rincones del mundo en representación de la Monarquía hispana.

\section{LA COMPOSICIÓN DE LAS CASAS NOBILIARIAS: PERFIL SOCIOECONÓMICO DE SUS MIEMBROS}

El mantener una casa en la que se integrase el mayor número de personas posible constituía un objetivo abiertamente ambicionado por los miembros de la alta nobleza castellana a fines del período medieval, y lo continuó siendo a lo largo de la Edad Moderna. No todos ellos estaban, sin embargo, en condiciones de poder financiar el sostenimiento de casas igualmente numerosas, y por consiguiente éste fue uno de los terrenos en que más se hizieron notar las diferencias de rango entre los diferentes miembros de este estamento. Por lo que respecta a la región en concreto que nos ocupa aquí, parece fuera de duda que la casa nobiliaria que ocupó una posición más 
elevada en la escala jerárquica "provincial" por su mayor patrimonio señorial, y por sus mayores fuentes de renta, fue la de los duques de Medinaceli. En qué medida esta superioridad jerárquica se tradujo en el mantenimiento de una casa que integrase a un número sensiblemente mayor de personas, es algo que, sin embargo, no es problema fácil de resolver con las fuentes de información hoy por hoy disponibles. No estamos en condiciones, en efecto, de determinar siquiera de forma aproximada el número de personas que llegaron a tener a su servicio los duques de Medinaceli en las últimas décadas del siglo XV y en las primeras del XVI. Algunos indicios sugieren, no obstante, que debió ser apreciablemente más elevado que el de personas empleadas en otras casas nobiliarias de la región soriana. Así, por ejemplo, cabe destacar que la duquesa de Medinaceli, doña Mencía Manuel, primera esposa del duque Juan de la Cerda, que otorgó su testamento en 1504, reconoció en él que entonces tenía a su servicio diez pajes, siete mujeres mayores, que permanecían, no obstante, solteras, y otras ocho doncellas, además de, al menos, dos esclavas, $y$ otras servidoras, entre las que figuraba una enana ${ }^{3}$.

La organización de las casas nobiliarias objeto de atención en el presente trabajo no nos resulta bien conocida, porque el tipo de documentación que hemos tenido a nuestra disposición no ha resultado particularmente rica en informaciones que permitan profundizar en el conocimiento de esta cuestión. Sí podemos afirmar que a grandes rasgos todas las casas respondían a un mismo modelo, e integraban a oficiales con idénticas, o muy parecidas, denominaciones, que muy probablemente desempeñarían funciones similares, aunque casi nunca nos resultan suficientemente bien conocidas, por falta de detalle en las informaciones proporcionadas por las fuentes documentales ${ }^{4}$. En todas ellas coexistieron individuos de muy variada extracción social, posición económica y procedencia geográfica. Hubo por un lado, sin contar a los miembros segundones de la propia familia señorial, que en ocasiones llegaron a ser relativamente numerosos, individuos de elevado rango sociopolítico, que ostentaban incluso la condición de señores de vasallos, los cuales solieron desempeñar los oficios principales dentro de la casa, bien de carácter doméstico o bien relacionados con el gobierno del señorío . Y, en el extremo opuesto de la escala jerárquica, las casas que aquí estamos tomando en consideración también integraron en su seno a esclavos y esclavas, de origen foráneo, que, pese a su desafortunada situación de privación de libertad, que los rebajaba en el terreno jurídico a la simple condición de un bien mueble, en determinadas ocasiones llegaron a hacerse merecedores de la estima de sus señores que, en premio a los forzados servicios que les prestaron en vida, a

${ }^{3}$ Copia del testamento de la duquesa de Medinaceli, doña Mencía Manuel, otorgado en Medinaceli, 9-VIII-1504, en AChV(=Archivo de la Chancillería de Valladolid), P.C. (= Pleitos

${ }^{4}$ Una visión global sobre los modelos de organización de las casas nobiliarias en la Castilla bajomedieval en Isabel BECEIRO PITA, Criados, oficiales y clientelas señoriales en Castilla (Siglos $X I-X V)$ "Cuadernos de Historia de España", 75 (1998-99), pp. 59-84. Entre las monografías dedicadas al estudio de las casas nobiliarias en otros reinos europeos cabe destacar para Inglaterra, K. MERTES, The English Noble Household. 1250-1600, Oxford, Basil Blackwell, 1988 . 
la hora de redactar sus testamentos decidieron concederles la libertad, efectuándoles incluso generosas donaciones de dinero. Así, por ejemplo, la condesa de Monteagudo Isabel de Zúñiga, esposa del primer conde, Pedro de Mendoza, en su testamento del año 1505 dispuso que los esclavos que ella poseía conjuntamente con su marido fuesen liberados a la muerte de éste. Además, a una esclava llamada Ana Luçia, que ella y su marido habían recibido como regalo del rey Enrique IV, le donó $15.000 \mathrm{mrs}$. para que se casase con un oficial, a otra esclava llamada Çiria le donó $16.000 \mathrm{mrs}$. y a un esclavo llamado Juan de Sevilla le mandó 5.000 mrs., además de $3.000 \mathrm{mrs}$. para cada uno de sus hijos e hijas ${ }^{5}$. Por su parte, la duquesa de Medinaceli, doña Mencía Manuel, en su testamento del año 1504 dispuso conceder la libertad a una esclava suya llamada Esperanza, a la que además hizo donación de $20.000 \mathrm{mrs}$. para que se casase ${ }^{6}$.

\section{Ascenso de familias hidalgas en el seno de las casas nobiliarias}

La presencia de señores de vasallos en las casas de miembros de la alta nobleza, siempre que no se tratase de algún segundón de la propia familia señorial, que hubiese recibido en los repartos de herencia algún señorío no integrado en mayorazgo ${ }^{7}$, no fue ciertamente un fenómeno muy frecuente, pero se dieron algunos casos que conviene recordar aquí, para dar idea de la extrema diversidad de condiciones que coexistieron en las grandes casas señoriales sorianas a fines de la Edad Media entre las personas que prestaban servicios en ellas. La casa que mayor número de señores de vasallos llegó a integrar fue la de los duques de Medinaceli, aunque en honor a la verdad se ha de hacer constar que algunos de ellos llegaron a serlo precisamente gracias a su vinculación con la propia casa ducal. Así nos lo demuestra el caso de Juan de Torres, regidor de la ciudad de Soria, que estuvo al servicio del cuarto conde de Medinaceli, Gastón de la Cerda, y logró convertirse en señor de vasallos, en concreto de la villa soriana de Retortillo, que permaneció en manos de su linaje hasta el fin del Antiguo Régimen, gracias precisamente a una merced que le efectuó el propio conde en premio a sus servicios. Había obtenido Gastón de la Cerda una merced del rey Juan II el 20 de enero de 1453 , por virtud de la cual le hizo donación de 300 vasallos en la Tierra de Atienza, para compensarle por haber sido apresado por gentes del rey Juan de Navarra cuando combatía al servicio del monarca cstellano. Pocas semanas

\footnotetext{
10 .

${ }^{5} \mathrm{El}$ testamento de la condesa en AHN (=Archivo Histórico Nacional), Osuna, leg. 2023, $\mathrm{n}^{\mathrm{o}}$.

${ }^{6}$ Copia del testamento de Mencía Manuel en AChV, P.C. Alonso Rodríguez, D, 120-1.

${ }^{7}$ Este fenómeno se dio con relativa frecuencia. Sobre señoríos que tocaron en herencia a segundones del linaje Arellano aportamos información en Máximo DIAGO HERNANDO, Implantación territorial del linaje Arellano en tierras camero-riojanas a fines de la Edad Media, "Berceo", 120 (1991), pp. 65-82. Varios segundones del linaje Mendoza recibieron en herencia pequeños señoríos, tạles como Villasayas, Rèllo, Hinojosa de la Sierra y Tejado. Por fin, también segundones del linaje de La Cerda se convirtieron en señores de vasallos, de lugares como Miedes, Mandayona o Torrecuadrada, entre otros.
} 
después estos vasallos le fueron señalados al conde de Medinaceli en varias aldeas de la referida Tierra de Atienza, entre las que figuraba la de Retortillo. E inmediatamente después, el 21 de septiembre de 1453, éste procedió a ceder el señorío sobre esta villa a Juan de Torres, a quien calificó como su "primo" en el documento de donación, justificando su decisión en el deseo de compensarle por los "muchos y agradables servicios" que le había prestado durante el tiempo que había estado al cargo de la defensa de la fortaleza de Villarroya, en el reino de Aragón, que el conde había conquistado a las gentes del rey de Navarra ${ }^{8}$.

A excepción del regidor soriano Juan de Torres, no conocemos ningún otro caso de caballero al servicio de los condes o los duques de Medinaceli que recibiese como merced de éstos, en premio a sus servicios, algún señorío de vasallos. Y, a pesar de ello, hubo algún que otro señor de vasallos más entre sus servidores. Es el caso, por ejemplo, del caballero Gil de Andrade, mayordomo de la duquesa de Medinaceli, doña Mencía Manuel ${ }^{9}$, que fue señor del lugar de Sotillo, heredado de su abuela Beatriz de Torres, de Moranchel y de la fortaleza de Albalate ${ }^{10}$. Y también de García de Torres, alcaide de la fortaleza de la villa de Medinaceli, que fue señor de las villas de Renales y Alaminos, en la actual provincia de Guadalajara, y dejó en el momento de su muerte, en 1503, una sustanciosa herencia, de la que formaban parte importantes heredades de cereal y varios molinos, valorada en 15 millones de $\mathrm{mrs}^{11}$.

Entre los servidores de los condes de Monteagudo no tenemos noticia de la presencia de ningún señor de vasallos que no fuese miembro de la propia familia condal, y otro tanto cabe decir respecto a los servidores de los condes de Aguilar, señores de Cameros. Pero sí que hubo entre ellos caballeros hidalgos de alto rango, a algunos de los cuales conviene que dediquemos brevemente a continuación nuestra atención para conocer mejor el perfil social de los miembros más encumbrados de las grandes casas señoriales en la región soriana a fines de la Edad Media.

Por lo que toca a los señores de Cameros, del linaje Arellano, tenemos que hacia mediados del siglo XV, cuando era titular del señorío Juan Ramírez de Arellano, se asentaron en su villa de Yanguas varios hidalgos de

\footnotetext{
${ }^{8}$ Copia de los mencionados privilegios en AHPS (=Archivo Histórico Provincial de Soria), Ensenada, 9814.

${ }^{9} \mathrm{Se}$ le menciona entre los testigos al otorgamiento de su testamento por la duquesa Mencía Manuel, en Medinaceli 9-VIII-1504. También está presente otro mayordomo, García de Medrano. AChV, P.C. Ảlonso Rodríguez, D, 120-1.

${ }^{10}$ Noticias de interés para conocer el perfil socioeconómico de Gil de Andrade en AGS (=Archivo General de Simancas), EMR (=Escribanía Mayor de Rentas), Hojas e Informaciones, leg. 552. AChV, RE, C. 186 (XI-1503). Varios testigos estimaron que sus rentas anuales oscilaban entre 1.000 y 2.000 fanegas.

${ }^{11} \mathrm{El}$ inventario de los bienes de García de Torres, alcaide de la fortaleza de Medinaceli, fechado en 6-II-1503, en AChV P.C. Pérez Alonso, F. (=Fenecidos) C. 230-5. Toda esta herencia le correspondió heredarla a su único hijo, bastardo, Ruy Sánchez de Torres. Por las cuentas que se tomaron al curador de ește último, que administró su hacienda entre 1503 y 1509 , consta que la explotación del patrimonio heredado de su padre le proporcionó a Ruy Sánchez de Torres en estos seis años un total de $984.280 \mathrm{mrs}$. es decir, una media de en torno a $164.000 \mathrm{mrs}$. anuales. Ibidem.
} 
procedencia foránea, que, gracias al favor que les dispensaron a ellos y a sus familias este noble y sus sucesores, lograron un rápido ascenso social y económico, que a los más afortunados de entre ellos les terminó aupando a las posiciones de máxima preeminencia dentro de la sociedad política provincial soriana a partir de mediados del siglo XVI. Desde esta perspectiva puede considerarse paradigmática la trayectoria de Juan López de Río, modesto hidalgo originario del obispado de Mondoñedo, en Galicia, quien, tras abandonar su patria de origen en busca de mejores condiciones de vida, entró a mediados del siglo XV al servicio del señor de Cameros, Juan Ramírez de Arellano, quien le designó para que se hiciese cargo de la tenencia de la fortaleza de su villa de Yanguas ${ }^{12}$. Allí contrajo matrimonio con una doncella perteneciente a una familia de ganaderos trashumantes, que le llevó a interesarse progresivamente por la actividad de la cría de ganado ovino en régimen trashumante, orientada a la producción de lanas finas para su exportación, sentando así las bases para la futura prosperidad de sus descendientes, que llegaron a convertirse en los señores de la cabaña de mayores dimensiones y mejor reputación por la calidad de sus lanas en todo el partido mesteño soriano ${ }^{13}$. De hecho su hijo primogénito, Pedro González, de Río, ya fue un destacado señor de ganados trashumantes, que desarrolló una intensa actividad en el seno de la Mesta, pero ello no le impidió permanecer aún al servicio de los señores de Cameros, condes de Aguilar, que le encomendaron la tenencia de la importante fortaleza de Yanguas, que ya había tenido su padre. En la siguiente generación, sin embargo, varios de los hijos varones de Pedro González de Río, habiendo alcanzado ya una notable posición económica gracias a los beneficios que les había reportado su actividad como ganaderos trashumantes, consideraron llegado el momento de romper vínculos con la casa de Arellano, y hacia 1520 decidieron cambiar su residencia desde la villa de Yanguas a la ciudad de Soria, que les ofrecía mejores perspectivas para su promoción en el terreno sociopolítico. Y en poco tiempo dieron pasos decisivos en esta dirección, pues lograron convertirse en señores de vasallos, gracias a la adquisición del señorío de la villa de Almenar, al que varias décadas después se sumó el de la villa de Gómara, y acceder al regimiento de la ciudad de Soria, en el que, tras la adquisición por compra del oficio de alférez mayor, consiguieron reservarse la posición de máxima preeminencia, con derecho de asiento preferente a la derecha del corregidor, hasta el fin del Antiguo Régimen ${ }^{14}$.

\footnotetext{
${ }^{12}$ Todas las informaciones sobre Juan López de Río las tomamos de las declaraciones de testigos presentadas con ocasión de la tramitación del pleito de hidalguía de su nieto Diego de Río, vecino de Yanguas, en la Chancillería de Valladoliọ en 1532. En AChV, Hijosdalgo, C. 2967. Un resumen de las mismas en RAH (= Real Academia de la Historia), Salazar y Castro, D-25,
fols. $158 \mathrm{r}^{\circ}-\mathrm{v}^{\mathrm{O}}$.

${ }^{13}$ Vid. Máximo DiAgo HeRnANDO, Una explotación trashumante en la Castilla moderna: La cabaña de los Río de Soria, "Historia Agraria", 48 (2009), pp. 21-44.

${ }^{14} \mathrm{Vid}$. Máximo DIAGO HeRnANDO, Estrategias de ascenso social en la Castilla del siglo XVI. La familia Río en Soria, "Historia Social", 49(2004), pp. 3-27.
} 
Ninguna otra de las familias que estuvieron al servicio de los señores de Cameros y condes de Aguilar durante el siglo XV tuvo una trayectoria tan exitosa como la de los Río, pero, a menor escala, también varias de ellas consiguieron convertir su estancia al servicio de este linaje de alta nobleza en Yanguas en plataforma para su posterior promoción en los terrenos socioeconómico y político. Así, en primer lugar, conviene hacer referencia a otra familia ganadera que en bastantes aspectos ofrece en su trayectoria evidentes paralelos con la de los Río. Nos referimos a los González de Castejón, de Ágreda. En efecto, nos consta que Martín González de Castejón, caballero originario de esta última villa fronteriza con Aragón y Navarra, entró también al servicio del señor de Cameros, Juan Ramírez de Arellano, quien le encomendó la tenencia de la fortaleza de Nalda ${ }^{15}$. En 1488 era vecino de Yanguas, al igual que su hijo Diego González de Castejón, pero ambos decidieron entonces regresar a su villa natal de Ágreda, donde, no obstante tropezaron con la resistencia de la población local a volver a admitirles como vecinos, porque llegaban con gran número de ganados trashumantes que habían de competir con los del resto de los vecinos de la villa y Tierra por el aprovechamiento de los pastos en los términos realengos ${ }^{16}$. Vencieron, no obstante, las resistencias, y en adelante permanecieron radicados en esta villa realenga, donde llegaron a consolidarse como la familia más acaudalada y con posición más preeminente en el terreno sociopolítico, refrendada tras la adquisición por Martín González de Castejón, hijo mayor de Diego González de Castejón, del señorío de la villa de Velamazán, puesto a la venta por el poderoso linaje de alta nobleza de los Tovar. Y de este modo otra familia que había vivido a la sombra de los señores de Cameros en los tiempos turbulentos del reinado de Enrique IV logró con éxito abandonar la relación de dependencia respecto a esta poderosa casa nobiliaria para integrarse en el grupo oligárquico de un concejo de realengo, en este caso de segunda fila, como era Ágreda, aunque a medio plazo procuró reforzar también sus vínculos con las familias de la oligarquía de la ciudad de Soria, para hacerse un hueco en la sociedad política de la cabecera de la provincia, misión en la que sus esfuerzos también se vieron coronados por el éxito.

Podríamos traer a colación algunos otros ejemplos de familias que estuvieron al servicio de los Arellano durante el siglo XV, y que en los tiempos más pacíficos del siglo XVI prefirieron volver a residir a concejos realengos, abandonando toda relación de dependencia respecto a dicha casa. Pero, dado que nuestro objetivo principal en este momento no es ilustrar esta tendencia, sino más bien poner de manifiesto cómo el servicio a los señores de Cameros representó para un gran número de familias hidalgas a lo largo del siglo XV una magnífica plataforma para el ascenso en los terrenos socioeconómico y político, propondremos a continuación algunos otros ejemplos, que complementan los ya aludidos de las familias Río y Castejón.

\footnotetext{
${ }^{15}$ Noticia en RAH, Salazar y Castro, M-65, fol. 278.

${ }^{16}$ Vid. Máximo Diago HeRnANDo, Soria en la Baja Edad Media: Espacio rural y economía agraria, Madrid, Editorial de la Universidad Complutense, 1993, p. 140.
} 
Una trayectoria muy ilustrativa a este respecto es la de Pedro García de Cereceda, hidalgo originario de la comarca de Laredo, en la actual provincia de Cantabria, quien acudió de mozo a Yanguas para servir a Juan Ramírez de Arellano ${ }^{17}$, que llegó a depositar en él toda su confianza, encomendándole la gestión de su casa y hacienda, razón por la cual se le llegó a conocer también con el nombre de Pedro García de la Plata ${ }^{18}$. Su hijo Juan de Cereceda continuó al servicio de los Arellano, como maestresala del primer conde de Aguilar, Don Alonso de Arellano, y también durante un tiempo como alcaide de la fortaleza de Yanguas, que, como hemos visto, estuvo a su vez al cargo de miembros de la familia Río. Y, en la siguiente generación, dos hijos de este Juan de Cereceda continuaron al servicio de esta misma casa, desempeñando el uno el oficio de contador y el otro el de maestresala de los condes de Aguilar $^{19}$. A diferencia de los Río o de los Castejón, el linaje de los Cereceda arraigó, sin embargo, en la Tierra de Yanguas, consolidándose como uno de los principales propietarios de ganado trashumante de esta jurisdicción hasta el siglo XIX, mientras que sus vínculos con la casa de Arellano se fueron haciendo cada vez más tenues. En esta misma línea otra trayectoria de sumo interés la encontramos en la descendencia de Ruy Díaz de Fuenmayor, caballero originario de la ciudad andaluza de Baeza, que entró al servicio de Juan Ramírez de Arellano en la misma época que Juan López de Río y Pedro García de Cereceda. En muchos aspectos su biografía fue muy similar a la de estos últimos, pues, al igual que ellos, mostró un fuerte interés por la actividad de la cría de ganado ovino trashumante, orientada hacia la producción de lana fina para su exportación. Y, en efecto, entre su nutrida descendencia se contaron varios de los principales señores de ganados trashumantes de la región soriana a lo largo de los siglos XV y XVI, asentados no sólo en Yanguas sino también en Ágreda, en Soria y en otras jurisdicciones ${ }^{20}$. Algunos de sus descendientes permanecieron a su vez al servicio de la casa de Arellano, llegando a ocupar posiciones de notable influencia en su seno, como testimonia el caso de su hijo, el bachiller Fernando Díaz de Fuenmayor, quien, como indicaremos más adelante, fue alcalde mayor y testamentario del primer conde de Aguilar. Y otros buscaron suerte en América, como Alonso de Fuenmayor, nombrado obispo de Santo Domingo en $1532^{21}$.

\footnotetext{
${ }^{17}$ En 1451 desempeñaba las funciones de escribano, según consta por documento otorgado por Juana de Arellano, hija de Juan Ramírez de Arellano e Isabel Enríquez, esposa de Pedro de Estúñiga, señor de Monterrey, en el castillo de la villa de Yanguas, 13-Il-1451, en AHN, Diversos, Títulos y Familias, carp. 10, $\mathrm{n}^{\mathrm{o}} .117$.

${ }^{18} \mathrm{AChV}$, Hijosdalgo, 53-2. Se informa que el valle de Cereceda pertenecía a la jurisdicción de Laredo, y se hace referencia a la iglesia de San Martín de Cereceda.

${ }^{19} \mathrm{AChV}$, Hijosdalgo , 53-2. Un documento fechado en Yanguas, 12-IX-1493, en que Juan de Cereceda aparece identificado como maestresala del conde de Aguilar en AHN, Osuna, 2183-6-4.

${ }^{20}$ Vid. RAH, Colección Salazar y Castro, D-25, fol. 92 ${ }^{\circ}$. Vid. también AChV, Pergaminos, 21-3, Valladolid, 24-X-1495. Ejecutoria de hidalguía a favor de Antón Díez de Fuenmayor, vecino de Yanguas, y originario de Baeza.

${ }^{21}$ Manuel GIMÉNEZ FERnÁNDEZ, Bartolomé de las Casas, II, Sevilla, 1960, p. 1193.
} 


\section{Perfil socioeconómico de los principales oficiales de las casas nobiliarias}

Los individuos de superior rango social desempeñaron habitualmente los principales oficios domésticos dentro de las casas señoriales. Es el caso, por ejemplo, del oficio de maestresala. Nos consta que en más de un caso los designados para el desempeño de este oficio fueron individuos que habían entrado a servir en la casa de niños o adolescentes, en calidad de pajes, y al llegar a la edad adulta habían sido armados caballeros por sus señores. Así nos lo testimonia, por ejemplo, la trayectoria de Alonso de Oquina, individuo originario de Ágreda, quien, según sus propias declaraciones, había comenzado sirviendo como paje a Juan Ramírez de Arellano, señor de Cameros, siendo adolescente, hasta que fue adulto y este último le "encabalgó", es decir, le hizo caballero, tras lo cual pasó a servirle como su maestresala ${ }^{22}$. El desempeño del oficio de maestresala representaba en cierto sentido una suerte de premio por los servicios prestados a la casa en el desempeño de otras funciones consideradas más onerosas durante muchos años. Y así nos lo confirman algunas trayectorias, como, por ejemplo, la de Juan de Vallejo, individuo originario de Soria, quien tras permanecer durante ocho años sirviendo como paje al segundo conde de Monteagudo, Antonio Hurtado de Mendoza, terminó siendo nombrado por éste como su maestresala, oficio que desempeñó durante dos años ${ }^{23}$. También en la casa de los duques de Medinaceli algunos maestresalas nos consta que fueron individuos de elevado rango, pertenecientes a algunas de las más encumbradas familias hidalgas del ducado, como nos testimonia, por ejemplo, el caso de Íñigo de Torres, quien siendo maestresala del duque desempeñó las funciones de curador de su pariente Ruy Sánchez de Torres, señor de Almenar, hijo bastardo y único heredero del alcaide de Medinaceli, García de Torres, a quien ya nos hemos referido con anterioridad ${ }^{24}$.

El de maestresala era uno más entre los varios oficios domésticos de elevado rango, desempeñados por hidalgos, en las casas de la alta nobleza soriana. Junto a él se han de destacar también los de repostero, despensero, camarero o mayordomo, oficios que en ocasiones también tuvieron una clara vertiente hacendística, lo que explica que con frecuencia los desempeñasen individuos con importantes intereses en el mundo de los negocios, tanto mercantiles como financieros. Esto resulta bastante evidente en el caso de muchos mayordomos. De hecho la mayor parte de las casas que estamos aquí considerando llegaron a contar con más de un mayordomo simultáneamente, y varios de ellos pueden ser caracterizados como dinámicos hombres de negocios, a veces implicados en turbios manejos, como nos testimonio, por ejemplo, el caso de Gonzalo de Barnuevo, mayordomo del conde de Aguilar,

\footnotetext{
${ }^{22}$ Estas declaraciones de Alonso de Oquina en AChV, P.C. Lapuerta, F. C. 871-1.

${ }^{23} \mathrm{AChV}$, P.C. Fernando Alonso F. C. 1042-3. 922-4.

${ }^{24}$ Algunas referencias a su papel como curador de este menor en AChV, P.C. Masas, F. C.
} 
vecino de Nalda, quien fue acusado por otro vecino de esta villa riojana de haberle engañado en una operación que le permitió a aquél apropiarse de un importante número de carneros. En concreto García Ruiz, vecino de Nalda, acusó al referido Gonzalo de Barnuevo de haberle propuesto que, para que sus acreedores no le fatigasen exigiéndole el pago de las cantidades de dinero que les adeudaba, le hiciese a él una donación fingida de unos 350 carneros que tenía para la provisión de las carnicerías de Nalda, que estaba a su cargo, para que no cayesen en poder de los acreedores, con la condición de que luego se los restituiría. García Ruiz confió en él, y le entregó los carneros, pero luego Gonzalo de Barnuevo dispuso de ellos como si fuesen suyos propios, llegando incluso a venderlos. García Ruiz por su parte fue llevado a la cárcel a petición de sus acreedores, y cuando requirió a Gonzalo de Barnuevo que le devolviese los carneros para que con ellos pudiese atender las demandas de estos últimos, tropezó con la negativa de éste a sus requerimientos, por lo que se vio obligado a solicitar amparo ante la propia Monarquía, dado que, por contar Gonzalo de Barnuevo con el apoyo de su señor el conde, no confiaba en poder alcanzar cumplimiento de justicia ni en Nalda ni en ningún otro lugar de sus estados $^{25}$. Pero, en honor a la verdad, conviene hacer constar que las relaciones entre el conde de Aguilar y su mayordomo Gonzalo de Barnuevo no siempre fueron de estrecha colaboración, sino que también se dieron graves enfrentamientos entre ellos, como bien lo prueba la denuncia presentada por este último en abril de 1524 contra Don Bernardino de Arellano, alcalde mayor del conde, por haberle encarcelado y confiscado todos sus bienes, por desavenencias que probablemente tenían relación con el rendimiento de cuentas de su gestión de la hacienda señorial ${ }^{26}$.

Los condes de Monteagudo reclutaron a al menos dos de sus mayordomos en el seno de la conocida familia judeoconversa adnamantina de los Laínez, a la que perteneció el célebre general de los jesuítas, sucesor de San Ignacio de Loyola al frente de la Compañía, y que destacó en las primeras décadas del siglo XVI por la activa participación de sus principales miembros en el mundo del comercio y las finanzas ${ }^{27}$. De esta familia procedía en primer lugar García Laínez, que era mayordomo del primer conde de Monteagudo, Pedro de Mendoza, en 1497, cuando el mercader vallisoletano García de Rueda le reclamó el pago de dinero que le debía por mercancías que le había vendido a crédito, y que es bastante probable que tuviesen por destino el abastecimiento de la casa condal ${ }^{28}$. Y también de ella formaba parte Alfonso

\footnotetext{
${ }^{25}$ AGS, RGS (=Registro General del Sello), VI-1524. Provisión al gobernador de Nalda, a petición de García Ruiz, vecino de dicha villa.

${ }^{26} \mathrm{AGS}, \mathrm{RGS}, \mathrm{IV}-1524\left(2^{\circ}\right)$. Provisión al corregidor de Soria, a petición de Gonzalo de Barrionuevo, vecino de Nalda, quien había denunciado que hacía más de 40 días que permanecía preso por orden del referido alcalde mayor.

${ }^{27}$ Abundantes referencias documentales de interés sobre esta familia en Carlos CARRETE PARRONDO y Carolina FRAILE CONDE, Los judeoconversos de Almazán. 1501-1505. Origen familiar de los Lainez, Salamanca, 1987.

${ }^{28}$ AGS, RGS, III-1497, fol. 201. Provisión a las justicias de Almazán para que obliguen a García Lainez, mayordomo del conde, a pagar las deudas que tiene contraídas con García de Rueda, mercader de Valladolid.
} 
Laínez, que era mayordomo de este mismo conde en el momento de su muerte, en 1504, junto con Juan Garcés, hidalgo originario de Ágreda ${ }^{29}$, y continuó después al servicio de su hijo, el segundo conde, Antonio de Mendoza, por cuenta del cual realizó compras de cierta emvergadura a mercaderes de Valladolid, que luego tropezaron con dificultades para cobrar las cantidades a ellos debidas por razón de las mercancías vendidas. Así, sabemos que el mercader vallisoletano Diego de Valladolid siguió pleito contra Alonso Laínez, a quien reclamó el pago de 198.969 mrs.que le debía por el valor de ciertas mercancías que le había vendido a crédito, y que este último se negaba a pagarle alegando que las referidas mercancías eran para su señor, el conde de Monteagudo, y era éste el que debía responder de su pago. Pero este argumento no fue atendido por los jueces de la Chancillería de Valladolid, que por su ejecutoria de octubre de 1525 ordenaron a Alonso Laínez que pagase los $198.969 \mathrm{mrs}$. que se le reclamaban ${ }^{30}$.

La familia de los Laínez también estuvo vinculada con el oficio de la mayordomía de la casa de los condes de Monteagudo por vía indirecta, a través de sus miembros femeninos, puesto que, en efecto, nos consta que otro de los mayordomos de esta casa a principios del siglo XVI, el hidalgo Juan de Peñaranda, que al mismo tiempo fue alcaide de la fortaleza de Moñux, estuvo casado con Jerónima Laínez. No sabemos mucho sobre el perfil socioeconómico del mayordomo Francisco Beltrán de Ocáliz, que estuvo desempeñando el oficio en los meses en que el segundo conde de Monteagudo, Antonio de Mendoza, estuvo ausente de su estado señorial por haberse embarcado en La Coruña en compañía del rey Carlos I en mayo de 1520 con destino a Flandes, aunque por indicios presumimos que pudo tener también origen judeoconverso, por los vínculos de parentesco constatados entre los Laínez y los Ocáliz ${ }^{31}$. En cualquier caso, le tocó ejercer el oficio en tiempos complicados, porque en el transcurso del referido viaje a Flandes el conde se vio obligado a hacer frente a cuantiosos gastos, y finalmente tuvo que pedir prestadas abultadas cantidades de dinero para atender sus múltiples compromisos. Por ello Francisco Beltrán de Ocáliz, que le había acompañado en su periplo por tierras europeas, debió regresar a Castilla con el encargo de su señor de recabar con urgencia recursos entre sus vasallos de Almazán para hacer frente a los apremios financieros que le abrumaban y amenazaban con precipitarle hacia la bancarrota, y permitirle al menos poder regresar a sus señoríos,

\footnotetext{
${ }^{29}$ Ambos mayordomos dieron cuenta de los bienes muebles que había en el momento de la muerte del conde, Don Pedro de Mendoza, en el palacio condal, para proceder a la elaboración del inventario post mortem. AHN, Osuna, leg. 2023-10.

${ }^{30} \mathrm{AChV}, \mathrm{RE}$ (=Registro de Ejecutorias), C. 381, X-1525. Ejecutoria a petición de Diego de Valladolid, vecino de Valladolid, contra Alonso Laínez, vecino de Almazán.

${ }^{31}$ En concreto Luisa Laínez estuvo casada con Diego de Ocáliz, y de este matrimonio nacieron María Beltrán, Diego de Ocáliz, Hernando de Ocálız, Violante Coronel y Pedro Beltrán. Vid. Carlos CARRETE PARRONDO y Carolina FRAILE CONDE, Los judeoconversos de Almazán, cit.
} 
poniendo así fin a la terrible sangría financiera que le afectaba ${ }^{32}$. Y no fue tarea fácil, habida cuenta de la situación enormemente inestable en lo político $\mathrm{y}$ en lo social por la que entonces atravesaban las tierras de la meseta castellana, y muy en particular las del estado señorial de Almazán, donde se estaba librando una violenta pugna por el ejercicio del poder entre la condesa de Monteagudo y sus hermanos, por un lado, y Don Alonso de Mendoza, señor de Tejado, hermano menor del conde, apoyado por algunos otros influyentes miembros de la casa condal, por otro. De hecho en estos turbulentos meses en que el conde de Monteagudo estuvo ausente de su estado señorial, acompañando al rey en su primer periplo por tierras europeas, tuvo lugar en Almazán un desgraciado episodio que afectó a otro destacado miembro de la casa condal, el que había sido mayordomo del primer conde, Juan Garcés, que pone bien de manifiesto los peligros inherentes al desencadenamiento de feroces rivalidades en el seno de las casas nobiliarias en un momento en que el jefe de la casa estaba ausente, y no podía hacer sentir su autoridad para poner coto a los enfrentamientos. Nos referimos al hecho de que Juan Garcés, quien ya no era mayordomo, pero seguía ocupando una posición de notable influencia en el seno de la casa condal, pues al parecer estaba al cargo de la guarda de la fortaleza de la villa de Almazán, en noviembre de 1521 , encontrándose en el interior de dicha fortaleza ${ }^{33}$, fue atacado por la condesa de Monteagudo y sus hermanos, que al frente de un

${ }^{32} \mathrm{El}$ mayordomo Francisco Beltrán de Ocáliz presentó la solicitud de auxilio financiero a los vecinos del estado señorial de Almazán en nombre de su señor el conde, a principios de junio de 1521, en los siguientes términos: "Soy venido por mandado de su señoria de Flandes, donde su señoria queda. Y la prinçipal cabsa a que su señoria me envyo es a que os diga de su parte lo syguiente. Que ya sabeys commo su senoria paso en Flandes con su magestad a le servyr, y en las cosas de su entrada en Flandes y en las vistas del rey de Yngalaterra y en la coronaçion de su magestad, que fueron todas cosas señaladas, le fue forçado de señalarse y gastar lo que otros señores de su manera gastavan. Y ansi en esto como en los gastos hordinaryos de su casa y despensa y camara ha gastado en aquellas partes muchas contyas de mrs. Y que para todo ello, en un año y mas tiempo que ha que está allá, no se le ha dado mas de myli ducados, que el señor don Antonyo le envyo en una cedula. A cuya cabsa su señoria ha resçebido mucha afrenta y nesçesydad, y tanta que a seydo forçado de tomar dyneros a logro para comer, en que ha resçebydo perdida de muchos mrs. Y que viendo esto su señoria, me mandó que viniese a desyros que su voluntad es de venyrse a su casa y para ello tiene ya liçençia de su magestad, y despachado y concluydo todo aquello que le podria dethener, y no le falta otra cosa para venyr a su casa, plasiendo a nuestro señor, sino ducados con que pueda pagar algo de lo que allá deve, y desenpeñar sus prendas y palabra que de su señoria tienen algunas personas. Y que para ello ha menester hasta dos mill e quinientos ducados, porque lo que deve a otros mercaderes, venydo su señoria, dará horden de conplyrlo acá. Y con estos dos mill e quinientos ducados me mandó que a la ora me partyese por las postas, porque llegado yo su señoria no se deternya mas solo un dia. Ansi que yo os pydo señores de parte de su senoria que de sus rentas y hasienda, o de aquello de lo que mejor y mas brevemente se pueda complyr, me deys e hagays dar dicta destos dos myll e quinientos ducados con que yo me pueda luego partyr, y el conde my señor pueda venyr a su casa. Y demas del daño que su hasienda resçibirá en que esto no cumplays, os çertyfico que la persona y vida de su señoria resçiba mucha afrenta y peligro sy ay tardança en my yda con este despacho. Y, pues syempre señores le fuystes muy leales y buenos vasallos y socorristes nesçesydades en que no se podia perder mas de hasienda y dineros, justo es que socorrays agora tan estrema nesçesydad en que esta aventurada hazienda, vyda y honrra de vuestro señor natural, que en mas os será thenido que sy de tyerra de moros le redimyesedes. Y esto hos digo como testigo de vista, y como persona a quien duele esta llaga como a tan antyguo cryado desta casa". Archivo Municipal de Almazán, leg. 20.

${ }^{33}$ En la versión de los hechos que ofrecieron los parientes de Juan Garcés se sostuvo que éste se encontraba en noviembre de 1521 en el interior de la fortaleza de Almazán, "por mandado del conde de Monteagudo, entendiendo junto con otras personas que allí estaban en las cosas que al dicho conde tocaban, como criado suyo antiguo, sin hacer ni decir cosa por que mal ni daño hubiese de recibir”. AGS, RGS, I-1523. Comisión al doctor Cuevas. 
gran número de hombres armados le pusieron cerco. Ante tan abrumadora amenaza Juan Garcés intentó huir, para tratar de buscar refugio en su tierra natal de Ágreda, pero cuando se disponía a hacerlo fue apresado, y entregado a la condesa. Y poco después tuvo lugar su asesinato, en circunstancias poco claras, aunque fueron muchos los que acusaron directamente a la propia condesa de haber sido la instigadora del mismo ${ }^{34}$.

Los ejemplos aducidos bastan para demostrar la enorme influencia que en el seno de las casas nobiliarias objeto de consideración llegaron a ejercer los mayordomos, oficiales con importantes responsabilidades no sólo en asuntos económicos sino también con frecuencia en otros de evidente carácter político. Y otro tanto cabría decir de algunos de los que desempeñaron el oficio de contador, que en principio tenía un perfil hacendístico todavía mucho más marcado. Los contadores, en efecto, eran los encargados de atender los pagos de los sueldos de todo el personal que estaba integrado dentro de la casa señorial ${ }^{35}$, y de las demás libranzas que ordenasen los señores mediante cédulas debidamente firmadas. Y no se trataba de una tarea precisamente fácil, debido a que con frecuencia los señores, en su falta de previsión y de conocimiento ajustado de sus reales fuentes de ingresos, ordenaban libranzas que no estaban respaldadas por la existencia de fondos suficientes con que pagarlas, lo que obligaba a los contadores a realizar todo tipo de maniobras, y en más de una ocasión a tener que echar mano de su propio dinero, arriesgándose a no poder recuperarlo, o a hacerlo con extraordinario retraso. Los contadores debían ser, pues, personas con cierta solvencia financiera, y de ahí que en bastantes casos, hasta 1492, los elegidos para desempeñar el cargo fuesen judíos. Es el caso, por ejemplo, de Simuel Pesquer, individuo originario de la judería de Soria, que sirvió como contador a Carlos de Arellano, señor de Cameros a principios del siglo XV, y fue padre de Ysaque Pesquer, destacado arrendador de impuestos al servicio de la Monarquía, y de la mujer del judeoconverso Juan Ramírez de Lucena, también conocido financiero y recaudador de impuestos durante el reinado de Enrique $\mathrm{IV}^{36}$. Y judío fue también el contador del siguiente señor de Cameros, Juan Ramírez de Arellano, que vivió en las décadas centrales del siglo XV. Nos referimos

${ }^{34}$ Una relación detallada del suceso, basada en la versión que del mismo dieron los herederos de Juan Garcés, en AGS, RGS, I-1523. Comisión al doctor Cuevas, juez pesquisidor, a petición de Cristóbal, García y Miguel Garcés, hermano e hijos de Juan Garcés, difunto, vecino de Agreda.

${ }^{35}$ Juan de Angulo, vecino de Cuéllar, presentó una demanda contra el conde de Monteagudo, reclamándole el pago de $8.000 \mathrm{mrs}$. que le debía del tiempo que le había servido como trompeta en una capitanía. A la demanda el conde replicó que no estaba obligado a pagar nada porque el acostamiento se le había de librar en su contador o tesorero, que tenia cargo de pagar a su gente, y de este modo se acostumbraba a proceder en las casas de los grandes, "que así hacían a sus criados, con sólo librarlos en sus contadores y darles para ello sus nóminas y libramientos". AChV, RE, C. 269, XI-1511.

${ }^{36}$ Tomamos la noticia de que Simuel Pesquer fue contador del señor de Cameros, Carlos de Arellano, de una referencia en el testamento del regidor soriano Gonzalo Gil de Miranda, del año 1412, que publica extractado Miguel MARTEL, De la fundación de Soria, del origen de los doce linages y de las antiguedades desta ciudad (Facsímil del original conservado en la Biblioteca Nacional de Madrid), fols. $54 \mathrm{v}^{\circ}-56 \mathrm{v}^{\circ}$. Sobre la familia conversa de los Ramírez de Lucena Vid. Máximo DIAGO HERNANDO, El protonotario Lucena en su entorno sociopolítico. Nuevos datos sobre su biografía, "Sefarad", 53 (1993), pp. 249-272. 
a Symuel Bienveniste, vecino del castillo de Soria, quien, según declaraciones de testigos, "avia ganado mucha haçienda" gracias a haber servido como contador a este señor de Cameros durante muchos años ${ }^{37}$. Por lo que respecta a los Mendoza, señores de Almazán, y luego condes de Monteagudo, nos consta que también recurrieron a judíos para que cobrasen sus rentas ${ }^{38}$, aunque no disponemos de datos que confirmen que alguno de ellos desempeñase formalmente las funciones de contador. Sí nos consta, no obstante, que después de 1492 desempeñó este oficio algún judeoconverso, como es el caso de Diego Laínez, marido de Luisa Vélez, que fue precisamente tío del jesuíta Diego Laínez. Del mismo modo, también los condes de Medinaceli tuvieron a su servicio a lo largo del siglo XV a judíos que se encargaron de recaudarles algunas de sus rentas ${ }^{39}$. Y más adelante recurrieron a su vez a judeoconversos para que les sirviesen en el oficio de contador, como nos testimonia, por ejemplo, el caso de Juan de la Isla ${ }^{40}$. No todos los contadores procedieron, sin embargo, de la minoría judía o judeoconversa, sino que también los hubo procedentes de otros grupos sociales, como es el caso de Martín González, individuo originario de la villa serrana de Yanguas que terminó fijando su residencia en Logroño, al que se le conocen tratos con lanas ${ }^{41}$. Y otro ejemplo en este mismo sentido nos lo proporciona Gómez Ruiz de Mercado, que sirvió durante varias décadas de contador al segundo conde de Monteagudo, Don Antonio de Mendoza, el cual había iniciado su carrera profesional como escribano del número en la ciudad de Soria. Y se trató de un individuo que, como veremos, gozó de la máxima confianza de su señor, como lo prueba el hecho de que le designó para que durante su ausencia en Flandes a partir de mayo de 1520 actuase como gobernador de su estado señorial de Almazán, para gran disgusto de su mujer, la condesa de Monteagudo, doña María de Mendoza, hermana de la célebre María Pacheco, viuda del capitán comunero Juan Padilla, que encabezó la resistencia de Toledo a la Monarquía tras la batalla de Villalar. Y es que, en efecto, María de Mendoza, mostrando un talante muy próximo al de su belicosa hermana toledana, en ausencia de su marido, con el que mantuvo una relación en extremo tormentosa y tensa, no disimuló su ambición de hacerse con el gobierno de sus tierras. Y pronto puso

\footnotetext{
${ }^{37}$ Declaraciones de Juan Rodríguez de Soria, Pedro Fernández de Santa María y Gastón de San Juan, en AChV, P.C. Lapuerta, F. C. 871-1.

${ }^{38}$ En 1493 el Consejo Real comisionó al bachiller Portillo para que junto con Francisco de Tapia, corregidor de Soria, juzgara la licitud de los contratos que ciertos judíos habían traspasado al conde de Monteagudo, Pedro de Mendoza. Dichos contratos estaban relacionados con rentas del referido conde, que hasta 1492 habían estado cobrando algunos judíos. AGS, RGS, IV-1493, fol. 78.

${ }^{39}$ Por ejemplo en 1432 y 1433 Samuel Abenxuxe cobró en nombre del conde alcabalas, martiniega y otras rentas en la villa de Medinaceli y en las tres cuadrillas de su Tierra. Vid. M $^{\mathbf{0}}$. Luisa PARDO RODRÍGUEZ, Documentación del Condado de Medinaceli (1368-1454), Diputación Provincial, Soria, 1993, doc. $\mathrm{n}^{\circ} .163$.

${ }^{40}$ Carlos CARRETE, El tribunal de la Inquisición en el obispado de Soria (1486-1502), Salamanca, 1985. p. 113.

${ }^{41}$ Sobre su papel como mercader lanero Vid. AGS, RGS, IV-1488, fol. 89. Provisión dirigida a los justicias de Yanguas, para que determinen la demanda de Rodrigo de Ruego, vecino de Logroño, que había comprado ciertas sacas de lana a Martín González, contador del conde de Aguilar.
} 
manos a la obra para tratar de alcanzar este objetivo, ayudada por sus hermanos, como consecuencia de lo cual chocó frontalmente con otros miembros promimentes de la casa condal, como eran el ya referido Juan Garcés, traicioneramente asesinado, y el contador Gómez Ruiz de Mercado, designado gobernador por el conde ausente.

Un perfil próximo a los contadores presentarían los tesoreros, aunque son pocas las referencias de que disponemos para conocer la identidad de los mismos. Sólo cabe apuntar que los condes de Monteagudo también recurrieron a judeoconversos para el desempeño de este oficio, y más en concreto a la prolífica familia de los Laínez, a la que pertenecía Antonio Laínez.

Entre los miembros de las casas nobiliarias que disfrutaron de la máxima confianza de sus señores para el desempeño de funciones políticas, relacionadas con el gobierno de sus estados, cabe hacer una mención especial a los secretarios, que fueron personajes de variada extracción social, en los que con frecuencia pesó más su capacitación profesional que su propio rango social, derivado de su origen familiar, como factor desencadenante de su promoción en el seno de las casas señoriales. Conocemos los nombres de varios de los individuos que sirvieron como secretarios a los condes de Monteagudo en la época que aquí estamos considerando, aunque no siempre disponemos de informaciones adicionales que nos permitan profundizar en la caracterización de su perfil socioeconómico y político. Interesa recordar que uno de ellos, Alonso de Escobedo, fue denunciado por su propia esposa, que lo acusó de negarse a hacer vida matrimonial con ella, debido a que vivía públicamente con una manceba en las villas de Monteagudo y Almazán, aprovechando sin duda la impunidad que su condición de secretario del conde le proporcionaba ${ }^{42}$. De otros secretarios sólo conocemos el nombre, como es el caso de Luis de Madrid, y por lo que respecta a otros, en concreto Martín González de Castejón, podemos precisar algo más sobre su origen, ya que nos consta que procedía de una conocida familia hidalga de Ágreda, aunque nos ha resultado imposible determinar su grado de parentesco con los representantes más destacados de dicha familia que residían a principios del siglo XVI en la propia Ágreda, donde llegaron a despuntar como hacendados señores de ganados trashumantes, que gracias a la riqueza que les proporcionó su explotación lograron acceder en breve espacio de tiempo a la condición de señores de vasallos, mediante la adquisición por compra de la villa de Velamazán, según ya hemos informado con anterioridad. Los duques de Medinaceli, por su parte, también encontraron en sus secretarios a algunos de sus más estrechos colaboradores, como nos testimonia, por ejemplo, el caso de Martín de Mondragón, quien sirvió en este oficio durante muchos años al segundo duque, Juan de la Cerda.

Junto a los secretarios también encontraron buenas perspectivas para medrar en las casas nobiliarias los titulados universitarios con formación jurídica, que fueron los preferidos para el desempeño de los oficios de

\footnotetext{
${ }^{42}$ RGS, X-1503. Provisión a petición de María Álvarez, mujer de Alonso de Escobedo, secretario del conde de Montegudo.
} 
alcaldes mayores, corregidores o gobernadores, que eran los que ejercían la máxima autoridad en los estados señoriales, por debajo del señor, y podían conocer en grado de apelación de todas las causas conocidas en primera instancia por las justicias ordinarias. No podemos entrar aquí a dar cuenta de la identidad de todos los individuos que desempeñaron estos cargos, por lo que nos limitaremos a proporcionar algunos ejemplos destacados, que pueden considerarse paradigmáticos. Es el caso, entre otros, del bachiller Fernando Díaz de Fuenmayor, quien fue uno de los servidores más próximos al primer conde de Aguilar, Alonso de Arellano, al que sirvió durante muchos años como alcalde mayor de su estado señorial ${ }^{3}$, el cual, como prueba de la confianza que en él tenía depositada, en el testamento que otorgó en 1494 le designó como su albacea testamentario, junto con su esposa, la condesa ${ }^{44}$. Otros letrados que sirvieron como alcaldes mayores a la casa de Arellano fueron el bachiller Diego López de Enciso, que lo era en $1451^{45}$, o el bachiller Pedro Díez, que lo era en 1512, aunque excepcionalmente también desempeñaron el cargo individuos sin formación universitaria, aunque de elevado rango social, como es el caso de Bernardino de Arellano, miembro segundón del linaje, que durante un tiempo fue alcalde mayor o gobernador del estado en nombre de su sobrina, Ana Ramírez de Arellano, en la que había recaído la sucesión en 1522 cuando apenas contaba un año de edad. Y algo similar ocurrió en el estado señorial de Almazán, donde los alcaldes mayores letrados, como el bachiller Sancho de Santisteban, coexistieron con otros sin formación universitaria, pero de muy elevado rango social, como Hernando de Barrionuevo, caballero soriano de quien hablaremos más adelante.

Por debajo de todos estos oficiales de elevado rango, que formaban parte del más reducido círculo de personas de confianza del señor, había sirviendo en las casas de la alta nobleza soriana un elevado número de personas, difícil de cuantificar, de condición socioeconómica más modesta, que, en muy mayor medida que las personas de las que hemos tratado hasta ahora, permanecen en el anonimato porque, salvo excepciones, son muy pocas las informaciones que las fuentes nos transmiten sobre ellos. Dentro de los que pertenecían al estamento hidalgo habría que mencionar a los numerosos pajes, escuderos, doncellas y damas de compañía a los que con frecuencia se hace referencia en los testamentos de sus señores. Y a ellos habría que sumar los hombres de armas que, sin vivir en la casa del señor, dado que con frecuencia residían incluso en otras poblaciones, formaban parte del círculo de sus criados, porque cobraban regularmente sueldo de él. En efecto, los

\footnotetext{
${ }^{43}$ Ya figura como alcalde mayor en un documento de 1478. Carta de seguridad otorgada por Alonso de Arellano en Aguilar 12-VII-1478. AGS, Cámara-Personas, leg. 11. Lo seguia siendo en 1493 según se atestigua en ÂHN, Osuna, 3364-13. Documento otorgado en Yanguas, 12-IX1493.

${ }^{44}$ El testamento del primer conde de Aguilar se puede consultar en Miguel Ángel MoRENO RAMíREZ DE ARELlano, Señorío de Cameros y Condado de Aguilar. Cuatro siglos de régimen señorial en La Rioja (1366-1733), Logroño, Instituto de Estudios Riojanos, 1992, doc. nº . 6, pp.
205-209.

${ }^{45} \mathrm{AHN}$, Diversos, Títulos y Familias, carp. 10, no 117.
} 
miembros de la alta nobleza, para poder cumplir con sus obligaciones militares hacia el rey, y disponer de fuerza armada con la que defender sus intereses frente a otros nobles rivales en períodos de turbulencias e inestabilidad, recurrieron al procedimiento de pagar "acostamientos" a caballeros y peones, a cambio del compromiso de éstos de acudir a sus llamamientos pertrechados para el combate, siempre que se les requiriese. Así procedió, por ejemplo, el segundo duque de Medinaceli, Juan de la Cerda, con un vecino de esta villa, Juan del Águila, a quien, según su propia declaración, le estuvo pagando un "acostamiento" de 20.000 mrs. anuales durante diez años, a cambio de que acudiese a servirle con cierto número de lanzas, es decir con varios hombres equipados para el combate, cuando lo necesitase. Pero, llegado el momento de haberle requerido para que le sirviese con dichas lanzas en la expedición de conquista del reino de Navarra en 1512, no cumplió con su obligación y dejó de acudir, por lo que el duque le condenó a pena de destierro $^{46}$. Y este mismo problema se le había planteado varias décadas antes a su predecesor, el primer duque de Medinaceli, quien en 1479 denunció que, habiendo estado pagando durante muchos años "acostamiento" a varios vecinos de Soria, Molina de Aragón y sus respectivas Tierras, al haberles requerido para que acudiesen a incorporarse al ejército que había de enviar a combatir contra el rey de Portugal, en cumplimiento de la orden que había recibido de los Reyes Católicos, muchos no quisieron acudir al llamamiento, y otros, aunque en un principio sí acudieron, luego se volvieron a sus casas sin entrar en combate ${ }^{4}$.

En los niveles más modestos de la escala jerárquica de las casas nobiliarias, situados sólo por encima de los esclavos, se encontraban los lacayos que desempeñaban las funciones de menos prestigio, en muchos casos consideradas incluso degradantes, como eran todas las relacionadas con la limpieza de la casa y de los establos, el cuidado de los caballos y del resto del ganado, la preparación de los alimentos para su consumo en las ocasiones ordinarias y extraordinarias o la recogida de las piezas de caza en las jornadas de montería, entre otras muchas. Y junto con ellos también servían en dichas casas otros muchos profesionales, tales como sastres, boticarios, médicos, cirujanos o barberos, quienes, no obstante, presumimos que debían atender al mismo tiempo a muchos otros clientes de fuera de la casa, aunque los documentos apenas nos informan al respecto.

\footnotetext{
${ }^{46} \mathrm{AChV}$, RE, C. 296, VI-1514. Ejecutoria en el pleito entre Juan de la Cerda, duque de Medinaceli, de una parte, y Juan del Aguila, vecino de Medinaceli, de otra. La Chancillería levantó la pena de destierro que había sido decretada por el duque.

${ }^{47}$ AGS, RGS, VIII-1479, fol. 85. Provisión a las justicias de Soria y Molina.
} 


\section{La remuneración de los servidores en las casas nobiliarias}

El capítulo de la remuneración del personal de las distintas escalas que estaba al servicio de los miembros de la alta nobleza nos resulta en líneas generales bastante mal conocido, tanto en lo que se refiere a cuantías de los sueldos como a modalidades de pago de los mismos. Noticias aisladas nos llevan a presumir que se dieron grandes diferencias en las cuantías asignadas a cada miembro de la casa en concepto de "acostamientos, raciones y quitaciones", correspondiendo las más elevadas a los segundones de la propia familia señorial. Así, por poner un único ejemplo ilustrativo, recordaremos que a D. Pedro de la Cerda, hermano del segundo duque de Medinaceli, Juan de la Cerda, éste le asignó 100.000 mrs. anuales de ración y quitación, aunque luego de hecho no se los pagó, alegando que en su casa sólo cobraban raciones y quitaciones quienes vivían regularmente con él, y su hermano, que estaba avecindado en Valladolid, no lo había hecho. Pero Don Pedro de la Cerda no admitió la validez de este argumento, y por ello pleiteó contra su hermano el duque en la Chancillería de Valladolid, reclamándole el pago de los referidos 100.000 mrs. anuales, que entendía que debía cobrar independientemete de que viviese con él o no ${ }^{48}$.

Por lo que se refiere a los procedimientos de pago, cabe afirmar, basándonos en las noticias proporcionadas por los testamentos y por la documentación de los pleitos que se siguieron ante los tribunales, en especial ante el de la Chancillería, que los miembros de la alta nobleza pagaron de forma muy irregular a sus criados, se desentendieron de abonarles puntualmente sus emolumentos, descargando en sus contadores o tesoreros la responsabilidad de hacerlo, hubiese o no fondos disponibles para ello, y como consecuencia llegaron a adeudarles cantidades importantes de dinero por sueldos impagados. Resulta frecuente encontrar en los testamentos de estos nobles, tanto de los titulares del señorío como de sus esposas, numerosos epígrafes en que los otorgantes reconocían tener contraídas deudas con criados de toda condición, desde mayordomos y secretarios hasta mozos de espuelas, algunos de los cuales hacía muchos años que habían estado a su servicio, y ya ni siquiera se tenía seguridad de que continuasen vivos. Y por escrúpulos de conciencia dispusieron con relativa frecuencia que se les pagasen las cantidades adeudadas, a ellos en persona si se les localizaba vivos, o a sus herederos en caso de haber fallecido, o, si no hubiese herederos, que se destinase el dinero al pago de misas por el eterno descanso del criado o criada al que no se le había compensado en vida por sus servicios.

En otras ocasiones los señores reconocieron en sus testamentos que no habían remunerado a sus criados como merecían por los muchos servicios que les habían prestado, y por ello dispusieron hacerles alguna merced extraordinaria. Así, por ejemplo, el segundo duque de Medinaceli, reconoció

${ }^{48} \mathrm{AChV}$, P.C. Fernando Alonso, F. C. 1156-3. 
en su testamento que su secretario Martín de Mondragón le había servido durante mucho tiempo fielmente, pero no le había podido gratificar los muchos y leales servicios que de él había recibido, debido a "los muchos y grandes gastos de mi casa". Y por ello, para compensarle, había decidido hacerle merced de $45.000 \mathrm{mrs}$. de juro de por vida, que solicitó expresamente a sus sucesores que le siguiesen pagando, ratificándole la merced recibida ${ }^{49}$.

Otro procedimiento muy socorrido para suplir por vía extraordinaria las deficiencias en la regular remuneración de los servidores fue la concesión de generosas dotes, en particular a las doncellas que habían servido como criadas, en el momento de concertar su matrimonio, en bastantes casos con varones que también habían estado al servicio de la casa, y que de esta manera indirectamente recibían a su vez una compensación, en la dote que llevaba su esposa, que les correspondía administrar mientras durase el matrimonio.

De hecho las cuantías prometidas en dote por los miembros de la alta nobleza a algunas de sus criadas de más rango fueron en ocasiones muy elevadas, sobre todo cuando la criada en cuestión era a su vez de elevado rango. Como testimonio puede servir el ejemplo de una hija de Juan de Avellaneda, señor de Alcubilla y Valverde, pequeños señoríos de la merindad de Santo Domingo de Silos, al oeste de la Tierra de Soria, quien, habiendo servido de doncella al conde de Coruña, recibió de éste nada menos que 100.000 mrs. en dote, cuando contrajo matrimonio con un hijo del señor de Villasayas, Diego de Mendoza, hermano del primer conde de Monteagudo ${ }^{50}$.

No obstante, en honor a la verdad, se ha de hacer constar que tampoco las cantidades prometidas en dote se pagaron con puntualidad, y con frecuencia se dejó incluso de abonar una parte importante de las mismas. Así, por ejemplo, tenemos constancia de que la segunda condesa de Monteagudo, María de Mendoza, prometió a Inés de Provencio, mujer de Hernán Páez de Sotomayor, vecino de Guadalajara, "por muchos cargos que con ella tenía", 130.000 mrs. para ayuda de dote y casamiento de su hija Catalina de Sotomayor. Por razones que la documentación no precisa, la condesa, sin embargo, no cumplió su promesa y se resistió por todos los medios a su alcance a hacer efectiva la entrega del dinero, pese a que el propio rey Fernando el Católico le dirigió dos cédulas conminándola a que hiciese honor a su compromiso. Y por ello finalmente tuvo que ser enviado un juez ejecutor a Almazán para embargar bienes de la condesa a fin de hacer efectivo el pago a la referida Inés de Provencio de la cantidad que se le había prometido para casar a su hija ${ }^{51}$. El marido de María de Mendoza, el segundo conde de Monteagudo, Don Antonio Hurtado de Mendoza, quien, como ya hemos

${ }^{49}$ Copia del testamento de Juan de la Cerda, duque de Medinaceli, fechado en Cogolludo, 18-I-1544, en AChV, P.C. Alonso Rodríguez, D, 120-1.

${ }^{50} \mathrm{AChV}$, P.C. Z. y Balboa, F. C. 20-1.

${ }^{51}$ AGS, Cámara-Personas, leg. 22. Cédula del rey de Valladolid 4-VI-1513, dirigida a la condesa de Monteagudo. AGS, RGS , X-1514 $\left(2^{\circ}\right)$. Provisión al corregidor de Aranda-Sepúlveda. Se hace constar que por dos cédulas del rey se había ordenado a la condesa que pagase los 130.000 mrs. , y que después se había comisionado al corregidor de Soria para que fuese a Almazán a hacer la ejecución en bienes de la condesa. 
visto, tuvo que hacer frente a gravísimos problemas financieros como consecuencia de los grandes gastos en que incurrió durante su viaje a Flandes en compañía del rey, también se mostró igualmente remiso a abonar en su integridad las cantidades prometidas en dote a algunos de sus criados. Así, sabemos que a mediados de la década de 1530 le pusieron demanda en la Chancillería sus criados Juan Vallejo, que le había servido primero como paje y luego como maestresala, y su mujer Ana de Miranda, que había servido como doncella a su hija Isabel de Zúñiga, reclamándole el pago de 60.000 mrs. que les había prometido a ambos en concepto de dote y de remuneración por servicios prestados por el novio antes de contraer matrimonio ${ }^{52}$.

En cualquier caso, las partidas destinadas al pago de dotes de criadas debieron suponer en determinadas ocasiones una pesada carga para las finanzas de las casas nobiliarias. Como prueba baste recordar el caso de la duquesa de Medinaceli, doña Mencía Manuel, que en su testamento del año 1504 dispuso que a siete mujeres que tenía a su servicio, las de mayor edad, se les abonase a cada una para su casamiento 50.000 mrs., a otras cinco doncellas más jóvenes, $40.000 \mathrm{mrs}$. a cada una, y a otras tres doncellas más, por fin, $30.000 \mathrm{mrs}$. a cada una. De modo que, en conjunto, para el pago de las dotes de sus damas de compañía que permanecían solteras, la duquesa tuvo que emplear nada menos que 640.000 mrs., cifra a la que habría que sumar los $20.000 \mathrm{mrs}$. que dispuso que se diesen a una de sus esclavas, Esperanza, para que se casase. Y esta enorme cifra contrasta con los $40.000 \mathrm{mrs}$. que dispuso que se diesen a los diez pajes que entonces tenía a su servicio, a razón de 4.000 mrs. a cada uno. En honor a la verdad se ha de hacer constar, no obstante, que en otras ocasiones las cantidades prometidas en dote a las criadas fueron bastante más modestas, como nos testimonia el caso de Leonor de Fuenmayor, hija de Rodrigo de Fuenmayor, vecino de Yanguas, que recibió de su señora la condesa de Aguilar $12.000 \mathrm{mrs}$. cuando contrajo matrimonio a comienzos de la década de 1490 con un caballero soriano de elevado rango, Diego de Barrionuevo, hijo del alcaide Juan de Barrionuevo, señor del término despoblado de Blasconuño $0^{53}$.

\section{PROYECCIÓN POLÍTICA DE LAS CASAS NOBILIARIAS SOBRE LOS CONCEJOS REALENGOS}

Aunque, como hemos podido comprobar, las grandes casas nobles de la región soriana tendieron a integrar en su seno durante el siglo XV y en las primeras décadas del siglo XVI a personas de muy variada procedencia geográfica, en todo momento quienes estuvieron al frente de ellas mostraron un evidente interés por reclutar como servidores a vecinos de los concejos realengos más próximos a sus señoríos, con el evidente propósito de

\footnotetext{
${ }^{52} \mathrm{AChV}$, P.C. Fernando Alonso F. C. 1042-3.

${ }^{53}$ Así consta por carta de finiquito de recibo de dote, de Soria, 21-IX-1491. AChV, P.C. Lapuerta F. 1168-3.
} 
incrementar su influencia política y social sobre el conjunto de la región. Esta política les dio sus mejores frutos durante los reinados de Juan II y Enrique IV, cuando su capacidad de ejercicio del poder en los concejos realengos de la región soriana por vía indirecta, a través de los miembros de sus clientelas, alcanzó las más altas cotas de efectividad, alimentando su ambición y deseo de llegar a reducir también dichos concejos a la misma situación de pleno sometimiento a su autoridad de la que disfrutaban en sus villas de señorío. Buena prueba de ello la tenemos en las actuaciones del conde de Medinaceli, que se vio involucrado en una prolongada guerra con los vecinos de Ágreda y su Tierra, cuando, amparándose en un privilegio obtenido del rey Enrique IV, por el que le cedía la jurisdicción civil y criminal sobre este concejo, trató en vano de tomar posesión de él como señor jurisdiccional. Tras la consolidación en el trono de los Reyes Católicos, estos monarcas se esforzaron por poner freno a las ambiciones nobiliarias, prohibiendo a los oficiales de los concejos de realengo, y muy en particular a los regidores, entrar al servicio de miembros de la alta nobleza, y recibir de ellos cualquier tipo de remuneración en forma de "acostamiento", por entender que de ello podría resultar menoscabo para los intereses políticos y la libertad del concejo realengo donde desempeñaban sus oficios. En la práctica, sin embargo, esta prohibición distó de observarse con rigor, y de hecho los miembros de la alta nobleza en la región soriana continuaron reclutando a algunos de sus principales servidores entre vecinos de concejos de realengo como Soria o Ágreda, que en más de un caso simultanearon la prestación de servicios como "criados" a dichos nobles con el desempeño de destacados oficios de gobierno local en sus concejos de origen. Pero de esta costumbre no se derivaron consecuencias tan negativas para la autonomía e independencia de dichos concejos como las que había tenido durante los reinados de Juan II y Enrique IV, cuando la inestabilidad general reinante había propiciado que proliferasen más los abusos de todo género, en bastantes casos con derivaciones violentas.

\section{La casa de los señores de Medinaceli}

Durante el siglo XV los condes de Medinaceli tuvieron una intensa participación en la vida política de la región soriana, utilizando como base su extenso estado señorial, con capital en Medinaceli, pero sirviéndose también de la densa red clientelar que pusieron en pie, en la que procuraron integrar a influyentes vecinos de concejos realengos, en especial de los de Soria, Ágreda y Molina de Aragón. Centrándonos en el análisis del caso de Soria, cabe destacar en primer lugar entre los miembros de su grupo oligárquico que formaron parte de la clientela de estos condes al regidor Juan de Torres, el Viejo, a quien ya nos hemos referido con anterioridad al informar de cómo había recibido del conde Gastón de la Cerda el señorío de la villa de Retortillo, antigua aldea de Atienza. Este caballero, que no era oriundo de Soria sino que al parecer tenía sus orígenes en la comarca de Medinaceli, donde poseía un importante patrimonio en tierras, tras su avecindamiento en la ciudad del Duero a mediados del siglo XV pasó pronto a convertirse en uno 
de los miembros más influyentes de su grupo oligárquico, como lo prueba, por ejemplo, su designación en repetidas ocasiones como procurador de Cortes por Soria, en concreto para las asambleas de 1448-1449 en Madrigal, de 1455 en Segovia y Córdoba y de 1457-1458 en Madrid, siempre en compañía de Rodrigo de Vera, señor de Hinojosa de la Sierra, otro de los miembros más influyentes de la oligarquía soriana del momento. Y al mismo tiempo destacó también por ser uno de los miembros del regimiento soriano que en mayor grado gozó del favor de los reyes Juan II y Enrique IV, que le hicieron algunas importantes mercedes, entre las que cabe destacar la concesión de la tenencia de la fortaleza de Peñalcázar, una de las principales de la línea fronteriza con el reino de Aragón, cuando ésta se recuperó de las gentes del rey de Navarra que la habían tenido ocupada ${ }^{54}$.

A mediados del siglo XV, cuando Juan de Torres fijó su residencia en Soria, el conde de Medinaceli había conseguido incorporar a su clientela a otros varios caballeros y escuderos avecindados en esta ciudad, como bien ponen de manifiesto algunas provisiones otorgadas por el rey Juan II en 1446, en un momento en que dicho conde se había aliado con el rey Juan de Navarra en contra de Don Álvaro de Luna. Por este motivo dicho monarca autorizó al tenente de la fortaleza de Soria, Juan de Luna, el gran valedor en la región soriana de la causa de su pariente el Condestable Don Álvaro ${ }^{55}$, a que apremiase a todos los caballeros vecinos de Soria que viviesen con el conde de Medinaceli a que no le prestasen ningún tipo de apoyo, so pena de que si no obedecían les pudiese embargar sus caballos y armas, y desterrarlos de la ciudad $^{56}$.

Desafortunadamente la escasa documentación conservada no nos ha permitido identificar a ninguno de estos caballeros sorianos que vivían con el conde de Medinaceli. Luis de la Cerda, en 1446, aunque consideramos bastante probable que entre ellos se contase Diego López de Medrano, señor de Cavanillas y de la casa fuerte de San Gregorio, pues figura entre los testigos asistentes al otorgamiento de su testamento, en Medinaceli, el 6 de agosto de $1447^{57}$. Sí tenemos constancia, no obstante, que en un momento un poco posterior, en la década de 1460 , otro de los miembros más influyentes del ayuntamiento soriano, el regidor Gonzalo Gil de Miranda, había entrado en una estrecha relación de dependencia con el nuevo conde de Medinaceli, Luis de la Cerda, elevado al rango de duque en 1479. Y dicha relación le llevó incluso a mantener enconados enfrentamientos con los vecinos de la ciudad y la Tierra de Soria. Sabemos, en efecto, que estos últimos llegaron a derribar una torre que este regidor soriano había edificado en la aldea de

\footnotetext{
${ }^{54}$ Para más detalles sobre la trayectoria de este regidor soriano Vid. Máximo DiAGO HERNANDO, Los Torres, condes de Lérida: Trayectoria de un linaje de la oligarquía soriana entre los siglos XIV y XVIII, "Celtiberia”, 99 (2005), pp. 111 y ss.

${ }^{55}$ Vid. Máximo Diago HeRnANDo, El alcaide Juan de Luna: un hombre al servicio del Condestable Don Alvaro en la región soriana, "Celtiberia", 81-82 (1991), pp. 59-85.

${ }^{56} \mathrm{RAH}$, Salazar y Castro, leg. 14, carpeta $10, \mathrm{n}^{\mathrm{o}} .11 \mathrm{y} \mathrm{n} \mathrm{n}^{\mathrm{o}} .12$.

${ }^{57}$ Vid. $\mathrm{M}^{\mathrm{a}}$. Luisa PARDO, op. cit. doc. $\mathrm{n}^{\mathrm{o}} .200$.
} 
Miranda, y en sus enfrentamientos con él y con su señor, el conde de Medinaceli, tuvieron lugar otros muchos excesos, con robos y tomas, por ambas partes, hasta que finalmente accedieron a firmar las paces en el año 1469, comprometiéndose a observar lo acordado el conde y Gonzalo Gil de Miranda, por un lado, y los oficiales del concejo de la ciudad y Tierra de Soria, por otro ${ }^{58}$. Lamentablemente el documento que contiene el texto de la concordia que puso fin al conflicto no resulta muy explícito a la hora de precisar los motivos por los que Gonzalo Gil de Miranda y el conde de Medinaceli se habían enfrentado violentamente con los vecinos de Soria y su Tierra, aunque no cabe duda de que debieron ser muy graves, si tenemos en cuenta que llevaron a estos últimos a proceder al derribo de una fortaleza. En cualquier caso lo verdaderamente interesante de este episodio es que un regidor del concejo soriano llegó a declarar la guerra a sus propios convecinos, aliándose con un miembro de la alta nobleza que en aquellos momentos despertaba abiertamente los recelos de la población de los concejos realengos de la región soriana por sus afanes expansionistas, que quedaron crudamente puestos de manifiesto en los ataques lanzados contra los vecinos de Ágreda y sus aldeas para tratar de incorporar estos lugares a su estado señorial, y que también afectaron al concejo de Soria, aunque en menor medida, pues nos consta que se había apoderado de una de sus aldeas, la de Pinilla ${ }^{59}$.

También en los momentos más turbulentos del reinado de Enrique IV sabemos que algunos otros destacados caballeros sorianos sirvieron en la casa de Medinaceli. Es el caso de Juan de Barrionuevo, quien fue enviado por su señor el conde para que tratase de apoderarse de la fortaleza de Hinojosa de la Sierra, antigua aldea de la Tierra de Soria que había sido concedida en señorío en tiempos de Juan II al caballero soriano Rodrigo de Vera, gracias a sus buenas relaciones con el Condestable Don Álvaro de Luna, y que tras la muerte sin hijos legítimos de este último pasó a ser objeto de encarnizadas disputas entre diversos nobles. Aprovechando precisamente que este Juan de Barrionuevo era pariente y amigo de algunos de los que se encontraban en la mencionada fortaleza en los turbulentos meses que siguieron a la muerte de Rodrigo de Vera y de su esposa María Contreras, el conde de Medinaceli le encargó que se trasladase allí para entablar negociaciones con sus parientes y amigos a fin de que le cediesen el control de la misma. Si tenía éxito podía por esta vía facilitarle al conde el refuerzo de su posición en plena Tierra de Soria, al permitirle controlar un importante enclave en el sector serrano de la misma. Pero su vinculación con este poderoso noble, que tantos recelos despertaba en aquellos inestables momentos entre la población de los concejos de realengo, debió disuadir a quienes estaban apoderados de la fortaleza de

\footnotetext{
55.

${ }^{58} \mathrm{El}$ texto de la concordia firmada por ambas partes en RAH, Salazar y Castro, F-7, fols. 115-

${ }^{59}$ Sobre la ocupación de Pinilla por el conde de Medinaceli hay referencias en AGS, Consejo Real, 48-1, y AGS, RGS, VII-1484, fol. 61.
} 
Hinojosa de llegar a trato ninguno con este caballero soriano, quien consiguientemente fracasó en la misión que le había encomendado su señor ${ }^{60}$.

Tras la normalización de la vida política castellana como consecuencia de la consolidación en el trono de los Reyes Católicos, la casa de Medinaceli dejó a un lado en gran medida sus proyectos de ampliación de su estado señorial a costa de los concejos de Ágreda y Soria, pero no por ello renunció definitivamente a continuar teniendo entre sus servidores a vecinos de dichos lugares. Así, por ejemplo, tenemos constancia de que varios miembros destacados del linaje de los Morales de Soria estuvieron al servicio de los primeros duques de Medinaceli. Es el caso de Pedro de Morales, hijo del regidor soriano Hernán Morales de Santa María del Espino, que fue maestresala de Luis de la Cerda, primer duque de Medinaceli, y su alcaide de la fortaleza de Arcos, y de Hernán Morales de Santa María del Espino, que otorgó testamento en 1535, en el que declaró que su señor, el segundo duque de Medinaceli, Juan de la Cerda, le debía dinero de sus "acostamientos" de los años 1519,1520 y $1521^{61}$. Y también en otras destacadas familias de Soria reclutaron a algunos de sus servidores los señores de Medinaceli en las primeras décadas del siglo XVI, como nos ilustra el caso de García de Solier, contino del duque de Medinaceli, que era hermano de Diego de Solier, caballero que, si bien ciertamente no llegó a desempeñar oficios destacados en el concejo de Soria, como el de regidor, sí fue un personaje destacado de la sociedad soriana a principios del siglo XVI, que logró tomar a censo perpetuo un importante heredamiento del monasterio de Santa María de Valvanera en las inmediaciones de la ciudad de Soria, el de la Monjía ${ }^{62}$.

\section{La casa de los Mendoza, señores de Almazán}

Tanto o mayor interés que los condes y duques de Medinaceli mostraron a lo largo del siglo XV los Mendoza, señores de Almazán, por hacer sentir su influencia sobre el concejo de Soria, para lo cual recurrieron también al expediente de colocar a su servicio a miembros destacados de su grupo oligárquico. Aunque el carácter extremadamente fragmentario de la documentación conservada no nos permite hacer muchas precisiones al respecto, sospechamos que fue durante el reinado de Enrique IV cuando la presión ejercida por los señores de Almazán sobre la Tierra de Soria alcanzó las mayores cotas de intensidad, y cuando éstos lograron que mayor número de miembros del grupo oligárquico soriano entrasen a su servicio, a cambio de pagarles un "acostamiento". En efecto, nos consta por declaraciones de testigos, en principio bastante fiables, que durante gran parte del reinado de Enrique IV el señor de Almazán, Pedro de Mendoza, tuvo a su servicio, y

\footnotetext{
${ }^{60}$ Nos basamos en declaraciones del propio Juan de Barrionuevo, contenidas en las pruebas testificales en AChV, P.C. Z. y Walls, F. C. 303-1 y ss.

${ }^{61}$ Noticias en AChV, P.C. Pérez Alonso, F. C. 301-1.

${ }^{62}$ Sobre la condición de "contino" del duque de Medinaceli de García de Solier, hermano de Diego de Solier, hay referencias en AChV, P.C. Masas, F. C. 922-4.
} 
pagó "acostamiento", a varios regidores de Soria, en concreto a Ximén Álvarez de Calatañazor, Velasco de Barrionuevo, el de Abajo, Rodrigo de Morales y Fernando de Barrionuevo, y a otros influyentes caballeros que desempeñaron destacados oficios en el gobierno de esta ciudad y su Tierra, como era el caso del bachiller Pedro García Calderón, açesor de la Universidad de la Tierra, el doctor Pedro Álvarez de Morales, açesor de la ciudad, y Lope de San Clemente, fiel de la Universidad de la Tierra ${ }^{63}$. Ciertamente algunos de estos individuos, en concreto los regidores Ximén Álvarez de Calatañazor y Rodrigo Morales, nos consta que en momentos anteriores habían estado llevando "acostamiento" del tenente de la fortaleza de Soria, Juan de Luna, quien cayó en desgracia y fue privado de sus oficios por el rey Enrique IV en $1459^{64}$, por lo que consideramos probable que entrasen al servicio del señor de Almazán con posterioridad a esta fecha. En cualquier caso no resultó infrecuente en la época que determinados caballeros cambiasen una o varias veces de señor a lo largo de su vida. De hecho en el ámbito que estamos aquí analizando hemos podido constatar algunos casos significativos, y no sólo en el turbulento período de las décadas centrales del siglo XV, cuando los endémicos enfrentamientos entre bandos nobiliarios propiciaron las constantes mudanzas. También en el siglo XVI, bastante menos convulso, al menos a partir de 1521, encontramos ilustrativos ejemplos de modestos hidalgos que fueron cambiando de señor a lo largo de su vida. Es lo que hizo, en concreto, el hidalgo soriano Tristán de Vinuesa, procedente de una acaudalada familia de ganaderos trashumantes originaria de la aldea serrana de Gallinero, que a partir de mediados del XVI se integró en el grupo oligárquico soriano ${ }^{65}$. Este individuo se dedicó a la carrera de las armas, y como tal participó en la expedición a los Gelves, y a su regreso se vio involucrado en el conflicto de las Comunidades, en el que militó del lado de los rebeldes ${ }^{66}$. Pero, con anterioridad, ya había servido como criado al conde de Aguilar, según consta por un documento del año $1512^{67}$, y con posterioridad estuvo al servicio del segundo conde de Monteagudo, Don Antonio de Mendoza, quien le prometió la entrega de cierta cantidad de dinero en dote si casaba con una criada de su casa, Catalina de Porras, e incluso le prestó las

\footnotetext{
${ }^{63}$ Según declaraciones de testigos en AChV, P.C. Fernando Alonso F. C. 1128-1. Uno de los testigos, Diego de Avila, declaro que había acudido a servir a Pedro de Mendoza con su caballo y armas por su señor Lope de San Clemente, fiel de la Tierr de Soria, que llevaba acostamiento de aquél.

${ }^{64}$ Vid. Máximo DiAgo HeRnANDo, El alcaide Juan de Luna: un hombre al servicio del Condestable Don Alvaro en la región soriana, "Celtiberia", 81-82 (1991), pp. 59-85.

${ }^{65}$ Sobre la familia Vinuesa, de Gallinero, Vid. Máximo Diago HERnANDo, Caballeros y ganaderos. Evolución del perfil socioeconómico de la oligarquía soriana en los siglos XV y XVI, "Hispania", 184 (1993), pp. 451-95.

${ }^{66}$ Vid. Máximo DIAGO HERNANDO, Los ganaderos mesteños ante la revuelta de las Comunidades (1520-1522), "Boletín de la Real Academia de la Historia" (En prensa).

${ }^{67}$ Se le menciona como testigo al otorgamiento por Don Álvaro de Arellano de una carta de poder al bachiller Pedro Díez, alcalde mayor del conde de Aguilar, fechada en Logroño, 11-IX1512. Aparece copiada en los libros de actas del cabildo de la catedral de Calahorra. AHN, Servicio Nacional de Microfilm, rollo 1780.
} 
armas y pertrechos necesarios para que pudiese acudir a combatir al reino de Navarra $^{68}$.

Pero, volviendo al caso de Pedro de Mendoza, señor de Almazán que en los momentos finales del reinado de Enrique IV tuvo "en nómina" a la mayor parte de los oficiales de alto rango del concejo de Soria, interesa hacer constar que, según coincidieron en afirmar numerosos testigos, gracias a ello consiguió que en esta ciudad no se hiciese entonces otra cosa salvo lo que él mandaba, "ansí en el regimiento como fuera de él", circunstancia que aprovechó para apoderarse de diversos enclaves del sector meridional de la Tierra de Soria. Cabe incluso la posibilidad de que este ambicioso noble aspirase entonces a enseñorearse de la propia ciudad, para someterla a su jurisdicción, pues nos consta por las declaraciones de varios testigos que en un momento no precisado del reinado de Enrique IV llegó a poner cerco a la fortaleza realenga soriana al frente de un nutrido grupo de hombres armados.

Superada la inestabilidad del período final del reinado de Enrique IV, que dio alas a las ambiciones de los miembros de la alta nobleza castellana a todo lo largo y ancho del reino, los señores de Almazán, convertidos ya en condes de Monteagudo, moderaron bastante su actitud hacia el concejo de Soria, y evitaron inmiscuirse en sus asuntos internos de forma tan abierta como habían hecho en las décadas previas. Pero no por ello renunciaron a poder seguir ejerciendo sobre él una cierta influencia, y buena prueba de ello es que durante el reinado de los Reyes Católicos continuaron teniendo a su servicio a miembros destacados del grupo oligárquico de esta ciudad. Caso notable es el de Hernando de Barrionuevo, que fue fiel de la Tierra de Soria y diputado de la Hermandad por esta ciudad, que era cabeza de provincia, y al mismo tiempo desempeñó cargos de la máxima confianza del conde de Monteagudo, de quien ya su padre Hernando de Barrionuevo había estado llevando "acostamiento", en el gobierno de sus estados, como el de alcalde mayor de su estado señorial. Por este motivo un vecino de Soria llamado Juan de Osuna presentó denuncia contra él, acusándole de "tener vivienda con el conde de Monteagudo", y al mismo tiempo desempeñar oficios de gobierno en el concejo de Soria, contraviniendo así lo que disponía la real pragmática que prohibía a los oficiales de los concejos realengos vivir con grandes ${ }^{69}$. Esta vinculación con Hernando de Barrionuevo es la que podría explicar la implicación del conde de Monteagudo en los desórdenes que se plantearon en Soria con ocasión de la elección de la abadesa del monasterio de Santa Clara de esta ciudad hacia 1519. Desconocemos la causa concreta que los desencadenó, pero nos consta que el juez pesquisidor enviado por la Monarquía para entender en este asunto, el licenciado Ronquillo, alcalde de Casa y Corte, condenó a Hernando de Barrionuevo en ciertas penas pecuniarias, destierro de la ciudad de Soria y privación del oficio de fiel de la Universidad de la Tierra y de diputado provincial de la Hermandad por un

\footnotetext{
${ }^{68} \mathrm{AChV}$, P.C. Fernando Alonso, F. C. 3.798-3.

${ }^{69} \mathrm{AGS}, \mathrm{RGS}, \mathrm{XI}-1510$.
} 
año ${ }^{70}$. Y prueba que el conde de Montegudo mostró un indisimulado interés en este negocio el hecho de que llegase a presentar una petición ante el Consejo Real en relación al mismo, si bien el carácter lacónico del documento que nos informa sobre la misma nos impide de todo punto precisar los motivos de dicho interés ${ }^{71}$.

Además de Hernando de Barrionuevo, otro destacado caballero de este mismo linaje soriano estuvo recibiendo acostamiento del conde de Monteagudo por las mismas fechas. Se trata de Alonso de Barrionuevo, señor del término despoblado de Valdosma, y nieto del regidor Hernán Yáñez de Barnuevo, quien en el codicilo de su testamento, otorgado en Soria, el 4 de junio de 1515, declaró que el referido conde, su señor, le debía $30.000 \mathrm{mrs}$. por razón del "acostamiento" de seis años que no le había abonado, a razón de $5.000 \mathrm{mrs}$. por año $^{72}$. Otro miembro de una conocida familia hidalga soriana, aunque de menor rango que los Barrionuevo, que estuvo al servicio de los condes de Monteagudo a principios del siglo XVI fue Cristobal de Solier, quien desempeñó el oficio de veedor en la casa condal. Y entre los individuos de origen probablemente pechero habría que destacar la figura de Gómez Ruiz de Mercado, quien comenzó su carrera profesional desempeñando el oficio de escribano del número en Soria, que compatibilizó con el servicio a una de las principales familias de la oligarquía soriana, la de los Torres, pues sabemos que ejerció el cargo de soliçitador y administrador de Juan de Torres, alcaide de Ponferrada ${ }^{73}$. En 1520, sin embargo, renunció a la escribanía, para trasladar su residencia a Almazán, donde comenzó a servir al conde de Monteagudo como contador. Gracias al desempeño de dicho oficio llegó a ocupar una posición de enorme influencia en el entorno de este noble, hasta el punto de que le nombró gobernador de su estado cuando emprendió viaje a Flandes en compañía del rey en 1520. Tras el regreso del conde a Almazán sus relaciones empeoraron, pues en 1524 llegó a pedir una carta de seguro, que le pusiese a salvo de posibles agresiones de su señor, de quien se recelaba por el odio y malquerencia que le tenía ${ }^{74}$. Pero debió tratarse de un desencuentro pasajero, pues sabemos que continuó residiendo en Almazán al

${ }^{70}$ AGS, RGS, VII-1519. Provisión al corregidor de Soria. La sentencia del licenciado Ronquillo fue después enmendada por el Consejo Real, que conoció de la apelación de Hernando de Barrionuevo.

${ }^{71}$ AGS, RGS, III-1519. Provisión al licenciado Ronquillo, alcalde de casa y Corte, informándole de la petición presentada por Bernardino de Miranda, en nombre del conde de Monteagudo, en relación al negocio del alboroto y escándalo que había ocurrido en la ciudad de Soria con motivo de la elección de la abadesa de Santa Clara.

758-1 y 759-1.

${ }^{72}$ Copia del testamento y codicilo de Alonso de Barrionuevo en AChV, P.C. Varela, F. C.

${ }^{73}$ Noticias al respecto en AChV, P.C. Alonso Rodríguez, F. C. 1395-2 y Masas, F. C. 1581 y 158-2. Sobre la posición del linaje de los Torres en Soria Vid. Máximo DIAGO HERNANDO, Los Torres, condes de Lérida...

${ }^{74}$ AGS, RGS, IX-1524. 
servicio de los señores de la villa en el desempeño del oficio de contador, que todavía ejercía en 1546, cuando ya contaba 67 años de edad $^{75}$.

\section{La casa de los Arellano, señores de Cameros}

Los Arellano, señores de Cameros, también se vieron muy atraídos por la ciudad de Soria, hasta el punto de que uno de ellos, Carlos de Arellano, segundo señor de Cameros de su linaje, fue el único miembro de la alta nobleza que a lo largo de los siglos XV y XVI la eligió como lugar de enterramiento, pues sus restos fueron inhumados en una de las capillas del monasterio de San Francisco de esta ciudad ${ }^{76}$, donde también llegó a contar con un palacio para su residencia ${ }^{77}$. Nada tiene de extraño, por tanto, que entre sus servidores se encontrasen algunos de los más influyentes miembros de la oligarquía soriana, como el regidor Gonzalo Gil de Miranda, antepasado del caballero homónimo que formó parte de la clientela del conde de Medinaceli en la década de 1460, a quien nos hemos referido con anterioridad. El que fue criado de Carlos de Arellano murió hacia 1412, y apeló expresamente a este último en su testamento, dando así fe del estrecho vínculo que les había unido a ambos en vida ${ }^{78}$. Por su parte la viuda de Carlos de Arellano, Constanza Sarmiento, también contó entre sus principales hombres de confianza con miembros de la oligarquía soriana, como el doctor Pedro Álvarez de Morales, açesor de la ciudad de Soria, a quien designó como su testamentario en $1463^{79}$. Juan Ramírez de Arellano, que sucedió en el señorío de Cameros a Carlos de Arellano, reclutó a su vez a algunos de sus servidores entre miembros de familias de la oligarquía soriana, como Rodrigo Rodríguez de Villanueva y Sancho Rodríguez de Villanueva, caballeros del linaje de San Llorente, uno de los Doce Linajes de la ciudad de Soria, cuya familia ejercía el señorío sobre el lugar de Osonilla ${ }^{80}$. Y esta práctica persistió en las siguientes generaciones, pues a principios del siglo XVI miembros de varias destacadas familias de la oligarquía soriana nos consta que estaban al servicio de los condes de Aguilar. Es el caso de Rodrigo López de Salcedo, señor de

${ }^{75}$ Interesan sus declaraciones como testigo en 1536, cuando contaba con 57 años de edad, en AChV, P.C. Fernando Alonso, F. C. 1042-3. Y en 1546, cuando sostuvo que llevaba viviendo en Älmazán desde hacía 28 años, en AChV, P.C. Z. y'Walls, F. C. 1406-1.

${ }^{76}$ Noticia del enterramiento de Carlos de Arellano en el monasterio de San Francisco de Soria, en RAH, Salazar y Castro, M-47, fols. $32 \mathrm{r}^{\mathrm{O}}-34 \mathrm{v}^{\mathrm{o}}$.

${ }^{77}$ Vid. Máximo DIAGO HERNANDO, Soria y su Tierra como señorío de miembros de la familia real castellana. Siglos XIV-XVI, "Celtiberia”, 101 (2007), p. 48.

${ }^{78} \mathrm{El}$ testamento de Gonzalo Gil de Miranda en Manuel MARTEL, Canto tercero de " $\mathrm{La}$ Numantina” y su comento: De la fundación de Soria y origen de los doce linajes, Madrid, CSIC, 1968, pp. 134-136.

${ }^{79}$ El testamento de Constanza Sarmiento, en el que calificó a Pedro Álvarez de Morales, entonces todavía bachiller, como "amigo", en RAH, Salazar y Castro, M-47, fols. $32 \mathrm{r}^{0}-34 \mathrm{v}^{\mathrm{o}}$.

${ }^{80}$ Juan Ramírez de Arellano renunció en 14526.000 mrs. de juro en su criado Rodrigo Rodríguez de Villanueva. Sancho Rodríguez de Villanueva, fue merino de Fuentepinilla, villa de señorio de los Arellano. AChV, P.C. Perez Alonso, F. C.'117-2. Y en 1451 actuó como testigo al otorgamiento de un documento en el castillo de Yanguas por Juana de Arellano, hija de Juan Ramírez de Arellano. AHN, Títulos y Familias, carpeta 10, nº. 117. 
la casa fuerte de Aldealseñor, en Tierra de Soria, quien falleció hacia 1505 siendo tenente por el conde de Aguilar de la fortaleza de Cervera del Río Alhama, al frente de la cual le sucedió su hijo Rodrigo de Salcedo ${ }^{81}$; de Julián de Molina, hijo de Gonzalo de Molina, caballero soriano vinculado al linaje de los Beteta, tenentes de la fortaleza de la ciudad, que fue merino de la villa de Fuentepinilla, señorío de los Arellano ${ }^{82}$; y del escribano Sebastián de Morales, calificado por varios testigos como amigo íntimo del regidor Gonzalo Gil de Miranda, y que estuvo involucrado en un grave caso de corrupción ocurrido con ocasión de la campaña de conquista de Navarra en 1512, al cual también se le atribuyeron vínculos con el conde de Aguilar ${ }^{83}$.

En suma, pues, las noticias aportadas por una documentación que cabe calificar de excesivamente fragmentaria y puntual, no dejan lugar a dudas sobre el hecho de que los señores de Cameros, Almazán y Medinaceli mostraron durante el siglo XV y las primeras décadas del siglo XVI un interés persistente por establecer vínculos de afinidad política con miembros significados de familias de la oligarquía de la ciudad de Soria, que en más de una ocasión trataron de utilizar para incrementar su capacidad de ejercicio del poder en ésta o en determinados sectores de su Tierra, en especial los más próximos a sus señoríos. Por supuesto no sólo dirigieron su atención hacia las familias más prominentes, sino que también se interesaron por reclutar entre los vecinos de Soria y su Tierra hombres de armas de condición sociopolítica más modesta, con el simple objetivo de que les sirviesen en sus empresas militares cuando fuesen requeridos para ello, de la misma manera que los reclutaron en otros concejos realengos próximos a sus estados señoriales, como el de Molina de Aragón. Por lo demás, aunque nos hemos centrado en el estudio del caso del concejo soriano, se ha de advertir que las referidas tres casas nobiliarias tampoco desatendieron a las oligarquías de los otros concejos realengos, e incluso de algunos de señorío, colindantes con sus estados señoriales, para tratar de extender su radio de influencia política. Así, por un lado, los Arellano mostraron un particular interés por ciudades como Logroño o Calahorra, ambas de realengo, donde chocaron con otros linajes rivales, como el de los Manrique, condes de Treviño y duques de Nájera ${ }^{84}$. Los Mendoza de Almazán, por su parte, además de vecinos de Soria, también

\footnotetext{
${ }^{81}$ Reconstrucción de la genealogía de la familia Salcedo, que en los siglos XVI, XVII y XVIII fue una de las principales propietarias de ganado trashumante en Soria y su Tierra, en Origen y Descendencia de la Casa de la Torre de Aldealseñor, Zaragoza, Joseph Fort, 1750 (Hay un ejemplar de esta rara obra en la Biblioteca Pública de Soria).

${ }^{82}$ AGS, RGS, XI-1501 y IX-1505.

${ }^{83}$ Referencia a dichos vínculos en AGS, RGS, IX-1510. Cabe ponerlos en relación con el hecho de que era primo del merino de Fuentepinilla, lugar de señorío del conde en tierras sorianas, según consta por AGS, Cámara-Personas, leg. 18, Sebastián de Morales. Sobre la implicación de Sebastián de Morales, junto con otros altos oficiales del concejo de Soria, incluido el corregidor, en un grave caso de corrupción relacionado con la campaña de conquista del reino de Navarra en 1512 Viḍ. Máximo DIAGO HERNANDO, Las comarcas castellanas fronterizas con Navarra ante la conquista del reino en 1512, "Príncipe de Viana", 242 (2007), pp. 917-945.

${ }^{84}$ Vid. Máximo DiAGo HERNANDO, El poder de la nobleza en los ámbitos regionales de la Corona de Castilla a fines del Medievo: Las estrategias políticas de los grandes linajes en la Rioja hasta la revuelta comunera, "Hispania", 223 (2006), pp. 501-546.
} 
tuvieron entre sus servidores a varios vecinos de Ágreda, y los duques de Medinaceli, por fin, extendieron su influencia hacia concejos situados al sur de sus estados señoriales, como el ya mencionado de Molina de Aragón e incluso el de Cuenca, entre los realengos, y el de la ciudad de Sigüenza, entre los de señorío eclesiástico ${ }^{85}$.

\section{CONCLUSIÓN}

En este breve trabajo hemos tratado de analizar una faceta del funcionamiento y estructuración de las sociedades políticas en los ámbitos regionales de la Corona de Castilla a fines de la Edad Media, dando cuenta del papel que en las mismas desempeñaron las grandes casas nobiliarias. Para ello hemos escogido una región en particular, la que abarcaba el sector nororiental de la Corona, fronterizo con los reinos de Navarra y Aragón, que tenía como principal centro político a la ciudad de Soria. Y hemos seleccionado en concreto, para analizar la composición de sus respectivas casas, a los tres linajes de alta nobleza que tuvieron una más intensa presencia en esta región durante el siglo XV y en las primeras décadas del siglo XVI, los que en el reinado de los Reyes Católicos ostentaban los títulos de condes de Aguilar, condes de Monteagudo y duques de Medinaceli. Tomando como base la información proporcionada por una documentación bastante fragmentaria y dispersa, hemos comprobado cómo estas tres casas señoriales habían alcanzado un notable grado de desarrollo a fines de la Edad Media, al integrar a un elevado número de personas, entre las que se contaban muchas de elevado rango, incluso señores de vasallos. Hemos podido advertir también que el servicio en dichas casas proporcionó a bastantes familias hidalgas una plataforma para su promoción en el escenario político regional extraordinariamente valiosa. Y, al mismo tiempo, hemos constatado que, en contrapartida, los referidos tres linajes de alta nobleza manifestaron un interés persistente por integrar en sus clientelas a miembros destacados de las oligarquías de los concejos realengos más próximos a sus estados señoriales, en especial del de Soria. Esta práctica alcanzó su máxima intensidad en las décadas previas a la consolidación en el trono de los Reyes Católicos, aunque se mantuvo, con consecuencias menos perturbadoras para la estabilidad política de los concejos realengos, durante el reinado de estos monarcas y con posterioridad. Conforme fue avanzando el siglo XVI, sin embargo, el progresivo distanciamiento de los miembros de la alta nobleza respecto a sus estados señoriales, en los que pasaron a residir de forma cada vez más esporádica, por preferir hacerlo en la Corte, sobre todo después de que ésta quedó fijada en Madrid, propició que las ciudades realengas, y en este caso la de Soria muy en particular, por tener reservado el derecho de representación en Cortes de toda la provincia, terminasen desplazando a las villas capitales de los estados

\footnotetext{
${ }^{85}$ En 1506 Lope Sánchez de Anguciana, vecino de Sigüenza, era capitán del duque de Medinaceli, Juan de la Cerda. AGS, Cámara-Personas, leg. 26. Sigüenza, 5-III-1506.
} 
señoriales, que habían sido las sedes de las grandes casas de la nobleza, como principales puntos de referencia de las sociedades políticas provinciales. Por ello el interés de los miembros de las oligarquías de estas ciudades realengas por integrarse en las casas de la alta nobleza fue decayendo conforme avanzó la Edad Moderna, mientras que en contrapartida se dieron muchos casos de familias que, habiendo prosperado a la sombra de algún linaje de alta nobleza en villas de señorío durante el siglo XV, pasaron a residir en el siglo XVI en ciudades de realengo, para incorporarse pronto a sus grupos oligárquicos. Y, cuando la Monarquía puso a la venta oficios de regidor y otros que aseguraban asiento en los ayuntamientos de los concejos realengos, no fueron pocas las familias residentes en villas de señorío, de las que hacía mucho tiempo que sus señores se habían ausentado, que decidieron comprar alguno de dichos oficios, para de este modo lograr un mayor reconocimiento en la sociedad política provincial, sin abandonar su originario lugar de residencia. Familias de Almazán, como los González de Ocampo, o de Lumbreras, como los Sánchez Salvador, que en el siglo XVII adquirieron regimientos perpetuos en Soria, proporcionan buenos ejemplos ilustrativos de esta tendencia, que convendría analizar más en detalle en el futuro en nuevos trabajos monográficos. En cualquier caso el contraste entre un siglo XV en que las cortes señoriales de Almazán, Medinaceli yYanguas actuaron como polos de atracción para la población hidalga de los concejos realengos de la región y de fuera de ella, y un siglo XVI en el transcurso del cual estas mismas cortes fueron progresivamente decayendo, conforme se iban distanciando de dichas villas sus señores, consideramos que está suficientemente probado. Y aquí radicaría uno de los cambios clave en el modelo de estructuración de la sociedad política de la provincia soriana a comienzos de la Edad Moderna.

Fecha de recepción del artículo: abril 2009.

Fecha de aceptación y versión final: junio 2009. 